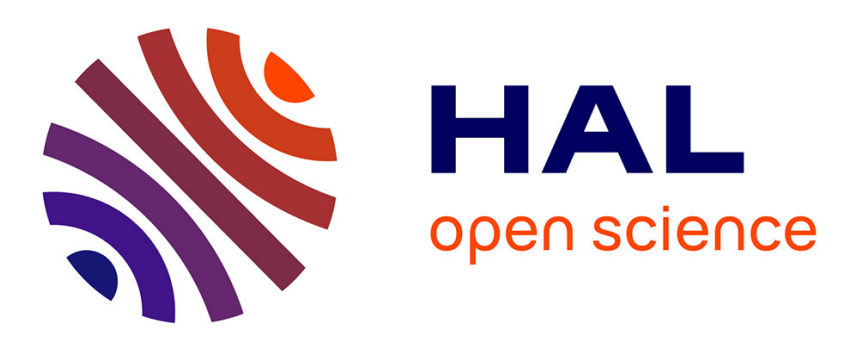

\title{
Semi-physical mean-value NOx model for diesel engine control
}

Carole Quérel, Olivier Grondin, Christophe Letellier

\section{To cite this version:}

Carole Quérel, Olivier Grondin, Christophe Letellier. Semi-physical mean-value NOx model for diesel engine control. Control Engineering Practice, 2015, 40, pp.27-44. 10.1016/j.conengprac.2015.02.005 . hal-01176532

\section{HAL Id: hal-01176532 \\ https://hal.science/hal-01176532}

Submitted on 15 Jul 2015

HAL is a multi-disciplinary open access archive for the deposit and dissemination of scientific research documents, whether they are published or not. The documents may come from teaching and research institutions in France or abroad, or from public or private research centers.
L'archive ouverte pluridisciplinaire HAL, est destinée au dépôt et à la diffusion de documents scientifiques de niveau recherche, publiés ou non, émanant des établissements d'enseignement et de recherche français ou étrangers, des laboratoires publics ou privés. 


\title{
Semi-physical mean-value NOx model for diesel engine control
}

\author{
C. Quérel ${ }^{\mathrm{a}}$, O. Grondin ${ }^{\mathrm{a}}$, C. Letellier ${ }^{\mathrm{b}}$ \\ ${ }^{a}$ IFP Energies Nouvelles, 1 et 4 avenue de Bois-Préau, 92852 Rueil-Malmaison Cedex- \\ France \\ ${ }^{b}$ CORIA UMR 6614, Université de Rouen, BP 12, 76801 Saint-Etienne du Rouvray Cedex \\ - France
}

\begin{abstract}
In this paper, a new physics-based model for the prediction of $\mathrm{NO}_{\mathrm{x}}$ emissions produced by diesel engines is presented. The aim of this work is to provide a Mean-Value Model (MVM) adapted for control design and online estimation. The proposed approach is based on the simplification of a zero-dimensional thermodynamic model. Only the main phenomena taking part in $\mathrm{NO}_{\mathrm{x}}$ formation are kept and they are described at a time scale of one engine cycle. A new model is proposed to estimate the burned gas temperature, known to have a strong impact on thermal $\mathrm{NO}_{\mathrm{x}}$ formation rate, from the first-order input variables on $\mathrm{NO}_{\mathrm{x}}$ emissions: burned gas ratio and start of combustion. This model is based on a discrete variable: the maximum burned gas temperature. The MVM for the maximum burned gas temperature, associated with a meanvalue $\mathrm{NO}_{\mathrm{x}}$ formation kinetic model, constitutes our mean-value $\mathrm{NO}_{\mathrm{x}}$ model. The adaptation of the burned gas temperature model enables to highly improve the accuracy of our crank-angle based model compared to purely physical models, and this accuracy is kept despite the simplification to a MVM. Thus, our MVM presents a sufficient accuracy for engine control purposes in both steady-state and transient operating conditions. This accuracy is achieved with only four parameters identified using a limited number of experimental data.
\end{abstract}

Keywords: Diesel engine, Nitrogen oxide emissions, Control-oriented model, Mean-value model, Transient operation 


\section{Introduction}

Automotive vehicles equipped with diesel engines have become more and more popular in the last decade. Their popularity is largely due to their high efficiency but these engines constitute a major source of Nitrogen Oxides $\left(\mathrm{NO}_{\mathrm{x}}\right)$ emissions. Future pollutant emission legislations are expected to impose stringent constraints on $\mathrm{NO}_{\mathrm{x}}$ emissions with a low emission limit $(80 \mathrm{mg} / \mathrm{km}$ for Euro 6 standard) and the introduction of a new driving cycle - the Worldwide harmonized Light-duty Test Cycle (WLTC) — which will be more representative of real driving conditions than the New European Driving Cycle (NEDC) currently employed in Europe. To reduce $\mathrm{NO}_{\mathrm{x}}$ emissions produced by diesel engines, advanced combustion technologies such as Low Temperature Combustion (LTC) systems based on high levels of Exhaust Gas Recirculation (EGR), vehicle hybridization and $\mathrm{NO}_{\mathrm{x}}$ aftertreatment devices are often considered. Control strategies have been developed to optimize the benefits of these technologies. However, $\mathrm{NO}_{\mathrm{x}}$ emissions are not directly taken into account in the controllers. To improve engine control in terms of $\mathrm{NO}_{\mathrm{x}}$ emissions produced during transient operations, one possible solution is to integrate $\mathrm{NO}_{\mathrm{x}}$ oriented controllers based on suitable $\mathrm{NO}_{\mathrm{x}}$ models [1, 2]. State estimation of cylinder-out $\mathrm{NO}_{\mathrm{x}}$ emissions is also required in order to reduce the sensor cost for the control of $\mathrm{NO}_{\mathrm{x}}$ aftertreatment systems based on Selective Catalytic Reduction (SCR).

Several characteristics are required for a $\mathrm{NO}_{\mathrm{x}}$ model adapted for control design. First, we search to describe $\mathrm{NO}_{\mathrm{x}}$ formation at a time-scale of one engine cycle, using a so-called Mean-Value Model (MVM) [3]. The mathematical formulation of the model must be simple and compact. The calibration effort has to remain limited: the model must have only a few parameters and must require a few experimental data for its identification. It has to be easily adaptable for any kind of diesel engine. The model also must accurately estimate $\mathrm{NO}_{\mathrm{x}}$ emissions in steady-state operating conditions and also during engine transients. Note that for MVM, a relative error of about 5 to $10 \%$ is expected. The model must ensure a smooth interpolation and a physically plausible extrapolation. 
Finally, the input variables of the model have to be measured or estimated from measured variables obtained using sensors available in mass production engines.

A large number of $\mathrm{NO}_{\mathrm{x}}$ models can be found in the literature, from complex multi-dimensional Computational Fluid Dynamic (CFD) models to static maps. A state-of-the-art of $\mathrm{NO}_{\mathrm{x}}$ modeling is presented in [4]. The development of $\mathrm{NO}_{\mathrm{x}}$ models adapted for designing control strategies is oriented towards the use of mean-value semi-physical models, which appear to be a good compromise between simplicity and genericity [2, 5, 6]. These models are well accepted in the field of air system control. However, apart from some MVM, the existing $\mathrm{NO}_{\mathrm{x}}$ models are usually not able to fulfill all the objectives previously mentioned, and thus, are generally not adapted for control design. This is mainly due to the complexity of the phenomena involved in $\mathrm{NO}_{\mathrm{x}}$ production that makes the existing models valid for engine simulation but too complex for designing controllers. Moreover, the model requirements may change according to the objectives: $\mathrm{NO}_{\mathrm{x}}$ estimation for SCR control [7], control of the start of injection to limit $\mathrm{NO}_{\mathrm{x}}$ emissions produced during transient operations [2, [8], transient correction of the engine torque setpoint in hybrid vehicles [9].

The aim of this paper is to propose a mean-value $\mathrm{NO}_{\mathrm{x}}$ model adapted for control purposes. The development of this model is based on the simplification of a physic-based model. This paper is organized as follows. First, a two-zone zero-dimensional thermodynamic model is described, where $\mathrm{NO}_{\mathrm{x}}$ formation is completely decoupled from the combustion process. The limitations of such a purely physical approach in terms of complexity and accuracy in $\mathrm{NO}_{\mathrm{x}}$ estimation are discussed. Then, an adaptation of this model is proposed: a semi-physical model is developed to estimate the burned gas temperature while the rest of the model - in particular the calculation of the concentrations in the burned gas zone and of $\mathrm{NO}_{\mathrm{x}}$ formation rate - remains unchanged. The key point of the burned gas temperature model is the estimation of the maximum temperature - which is the single parameterized variable in the complete model - from the first-order input variables on $\mathrm{NO}_{\mathrm{x}}$ emissions. The choice of the input variables relies on a sensitivity analysis of $\mathrm{NO}_{\mathrm{x}}$ emissions to injection settings and ther- 
modynamic conditions in the intake manifold. A MVM is then derived from this adapted crank-angle based model. The MVM for the maximum burned gas temperature is kept and the $\mathrm{NO}_{\mathrm{x}}$ formation model is simplified to obtain a MVM estimating $\mathrm{NO}_{\mathrm{x}}$ emissions from the maximum burned gas temperature. Finally, the developed MVM is validated in both steady-state and transient operating conditions.

\section{Zero-dimensional thermodynamic model}

In this section, the zero-dimensional thermodynamic reference model is introduced to calculate $\mathrm{NO}_{\mathrm{x}}$ emissions produced by diesel engines using the extended Zeldovich mechanism. This model is employed to determine the key variables responsible for $\mathrm{NO}_{\mathrm{x}}$ production.

\subsection{Principle}

Zero-dimensional thermodynamic models are employed to simulate engine performances in terms of engine torque and pollutant emissions. These performances are computed from injection settings and thermodynamic conditions in the cylinder at Intake Valve Closing (IVC). The evolutions of the pressure $p_{c y l}$ and of the temperature $T_{c y l}$ in the cylinder are described by a system of first-order differential equations with two state variables

$$
\left\{\begin{array}{l}
\frac{\mathrm{d} p_{c y l}}{\mathrm{~d} \theta}=\frac{\gamma-1}{V_{c y l}}\left[\frac{\delta Q_{c o m b}}{\mathrm{~d} \theta}+\frac{\delta Q_{w}}{\mathrm{~d} \theta}+\sum_{j} \frac{\mathrm{d} n_{j}}{\mathrm{~d} \theta} h_{n, j}\right]-\frac{\gamma}{V_{c y l}} p_{c y l} \frac{\mathrm{d} V_{c y l}}{\mathrm{~d} \theta} \\
\frac{\mathrm{d} T_{c y l}}{\mathrm{~d} \theta}=T_{c y l}\left[\frac{1}{p_{c y l}} \frac{\mathrm{d} p_{c y l}}{\mathrm{~d} \theta}+\frac{1}{V_{c y l}} \frac{\mathrm{d} V_{c y l}}{\mathrm{~d} \theta}\right]
\end{array}\right.
$$

obtained from the conservation of mass and energy applied to the open system represented by the combustion chamber. The crank angle $\theta$ is the independent variable of the model, $V_{c y l}$ represents the volume of the combustion chamber and $\gamma$ is the ratio of specific heats. $\frac{\delta Q_{c o m b}}{\mathrm{~d} \theta}, \frac{\delta Q_{w}}{\mathrm{~d} \theta}$ and $\sum_{j} \frac{\mathrm{d} n_{j}}{\mathrm{~d} \theta} h_{n, j}$ are the Rate Of Heat Release (ROHR), the heat flow transferred at walls and the heat flow exchanged at intake and exhaust valves, respectively. With these models, the 
combustion process is described using identified or predictive models for the ROHR [10, 11].

In this paper, we focus on $\mathrm{NO}_{\mathrm{x}}$ emissions and on thermodynamic conditions in the burned gases where $\mathrm{NO}_{\mathrm{x}}$ are produced. As $\mathrm{NO}_{\mathrm{x}}$ are formed during the combustion process, when both the intake and exhaust valves are closed, only the phenomena occurring during the closed part of the engine cycle are modeled. Moreover, the ROHR is no more modeled but directly computed from the experimental cylinder pressure signal which is thus an input variable of our model. As a result, the system (1) becomes

$$
\left\{\begin{array}{l}
\frac{\delta Q_{c o m b}}{\mathrm{~d} \theta}=\frac{\gamma}{\gamma-1} p_{c y l} \frac{\mathrm{d} V_{c y l}}{\mathrm{~d} \theta}+\frac{V_{c y l}}{\gamma-1} \frac{\mathrm{d} p_{c y l}}{\mathrm{~d} \theta}-\frac{\delta Q_{w}}{\mathrm{~d} \theta} \\
T_{c y l}=\frac{p_{c y l} V_{c y l}}{R n_{c y l}},
\end{array}\right.
$$

where $R$ is the universal gas constant and $n_{c y l}$ the total molar quantity of gas in the cylinder. The use of the cylinder pressure as input enables not to cumulate $\mathrm{NO}_{\mathrm{x}}$ formation and combustion modeling errors. The cylinder pressure can be employed as input variable since this pressure is independent of $\mathrm{NO}_{\mathrm{x}}$ formation. Indeed, $\mathrm{NO}_{\mathrm{x}}$ production does not have any impact on the combustion process as the quantity of oxygen used for $\mathrm{NO}_{\mathrm{x}}$ production is negligible compared to the quantity spent for fuel oxidation (figure 1).

\subsection{Structure and main hypotheses}

The proposed model is composed of four sub-models (figure 2):

1. determination of the thermodynamic conditions (pressure, temperature, gas composition, mass of gas) in the cylinder at IVC which correspond to the initial conditions of the system;

2. computation of the ROHR and of the mean thermodynamic conditions in the cylinder which are required for the knowledge of the combustion progress and thus, for the modeling of the thermodynamic conditions in the burned gases; 


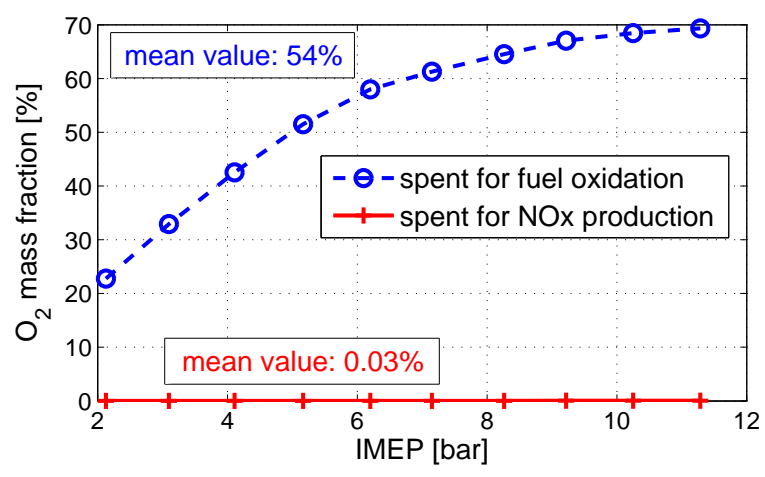

Figure 1: Oxygen quantities spent for fuel oxidation and for NOx formation versus Indicated Mean Effective Pressure (IMEP) for a given engine speed $\left(N_{e}=2500 \mathrm{rpm}\right)$. The values are given in mass fractions relative to the total mass of oxygen at IVC.

3. modeling of the thermodynamic conditions in the unburned and burned gases, and especially of the volume $V_{b}$, the temperature $T_{b}$ and of the concentrations $[i]_{e q}$ of the species $i$ in the burned gases, which are the input variables of $\mathrm{NO}_{\mathrm{x}}$ formation model;

4. computation of $\mathrm{NO}_{\mathrm{x}}$ emissions.

The main considered hypotheses are the following:

- The quasi-dimensional approach classically employed to describe the combustion process in internal combustion engines [12, 13] is used. The gases present in the cylinder are composed of unburned or burned gases. The combustion in diesel engines is inhomogeneous and is initiated at different places in the combustion chamber. However, in a final perspective of using the developed models for engine control, we do not search to describe the spatial repartition of $\mathrm{NO}_{\mathrm{x}}$ production in the cylinder so that all the zones where the combustion occurs are assimilated to a single zone. Consequently, the combustion chamber is described using an unburned gas zone, composed of fresh air and EGR, and a burned gas zone. 


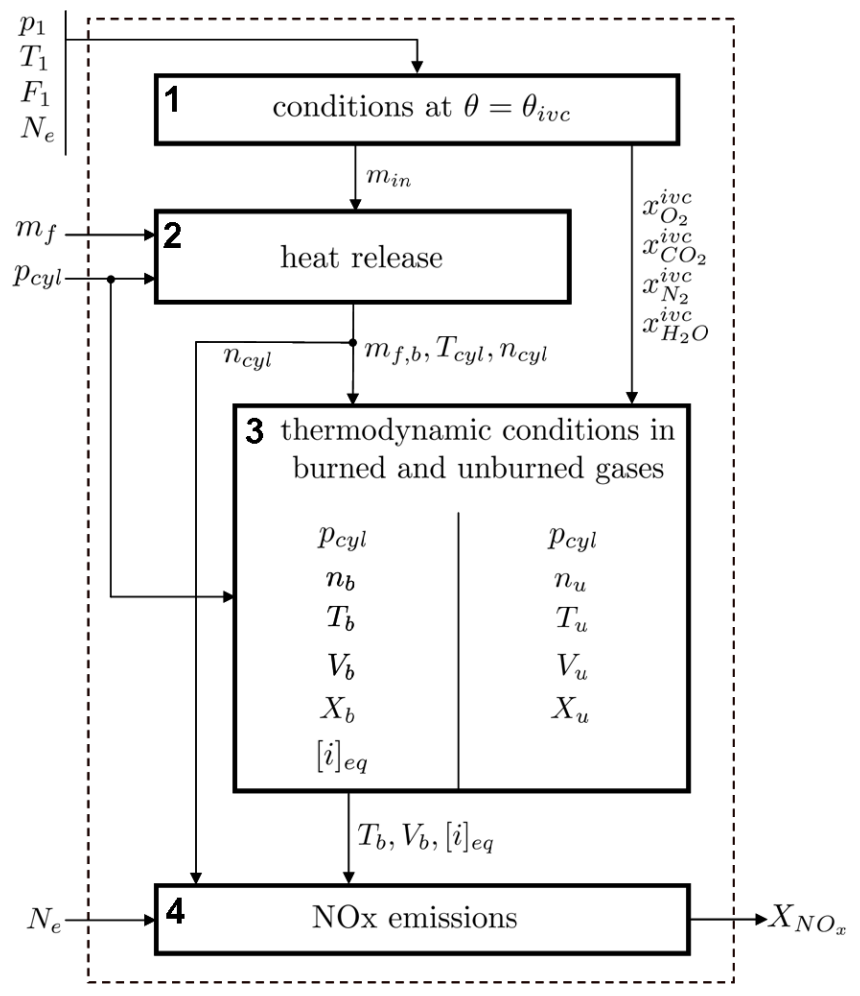

Figure 2: Structure of the reference model. 
The pressure and temperature are homogeneous in each zone (no spatial variations).

- The pressure is supposed to be homogeneous in the combustion chamber.

- A stoichiometric Air-Fuel Ratio (AFR) is considered in the reaction zone since diesel combustion occurs in the zones where the relative AFR is close to one [13].

- Combustion and dissociation reactions are supposed to be at equilibrium. This hypothesis is justified by the slow kinetics of $\mathrm{NO}_{\mathrm{x}}$ formation compared to the one of the combustion process [13, 14].

- $\mathrm{NO}_{\mathrm{x}}$ are assimilated to nitrogen monoxide (NO). $\mathrm{NO}_{\mathrm{x}}$ produced by diesel engines are composed of $\mathrm{NO}$ and nitrogen dioxide $\left(\mathrm{NO}_{2}\right)$. However, $\mathrm{NO}_{2}$ is mainly produced from $\mathrm{NO}$ and the molar quantity of $\mathrm{NO}_{2}$ formed is equal to the molar quantity of $\mathrm{NO}$ spent so that the molar quantity of $\mathrm{NO}_{\mathrm{x}}$ can be supposed equal to the molar quantity of NO produced [15].

- $\mathrm{NO}_{\mathrm{x}}$ formation is modeled using only the thermal mechanism proposed by Zeldovich. Four mechanisms have been identified for NO formation [13]: a thermal mechanism, a prompt mechanism, $\mathrm{NO}_{\mathrm{x}}$ formation via nitrous oxide $\left(\mathrm{N}_{2} \mathrm{O}\right)$ and $\mathrm{NO}_{\mathrm{x}}$ formation from fuel nitrogen. In standard diesel engine, the combustion occurs at high pressure and high temperature. Consequently, NO is mainly produced by the thermal mechanism which was proposed by Zeldovich [16] and extended by Lavoie et al. 17]. Thus, for sake of simplicity, only this mechanism is taken into account.

To summarize, the input variables of the model are the intake pressure $p_{1}$, the intake temperature $T_{1}$, intake Burned Gas Ratio (BGR) $F_{1}$, the total mass of injected fuel $m_{f}$, the engine speed $N_{e}$ and the cylinder pressure $p_{c y l}$. The 
volume $V_{b}$, the temperature $T_{b}$ and the equilibrium concentrations $[i]_{e q}$ of the species $i$ in the burned gases are the input variables of $\mathrm{NO}_{\mathrm{x}}$ formation model (figure22). Finally, $\mathrm{NO}_{\mathrm{x}}$ molar fraction in the cylinder exhaust $X_{N O_{x}}$ constitutes the output of the model.

The four sub-models are detailed in [18] and [19]. Only the main aspects are presented in this paper. In the following, the indices $u$ and $b$ refer to the unburned and burned gases, respectively.

\subsection{Thermodynamic conditions at IVC}

From the thermodynamic conditions in the intake manifold $\left(p_{1}, T_{1}, F_{1}\right)$, the first sub-model (figure 2) computes the variables describing the state of the mixing in the cylinder at IVC, and in particular the aspirated mass $m_{i n}$ and the mass fractions $x_{i}^{i v c}$ of the species $i$ present in the cylinder. Note that these conditions correspond to the initial conditions of the system since the combustion chamber is isolated from the air system between IVC and Exhaust Valve Opening (EVO).

The aspirated mass is computed from a cylinder filling model [13], according to

$$
m_{\text {in }}=\eta_{v} \frac{V_{d} p_{1}}{r_{\text {air }} T_{1}}
$$

where $V_{d}$ is the displaced volume, $\eta_{v}$ the volumetric efficiency and $r_{a i r}$ is the gas constant.

The composition of the gases in the cylinder at IVC corresponds to the one in the intake manifold. Intake gases are composed of fresh air and recirculated gases, the residual gases being neglected. The composition of the gases present in the cylinder at IVC results from the mixing between fresh air and EGR. Only the main species are considered in the aspirated gases: dioxygen $\mathrm{O}_{2}$ and dinitrogen $\mathrm{N}_{2}$ present in fresh air and in recirculated gases, carbon dioxide $\mathrm{CO}_{2}$ and water $\mathrm{H}_{2} \mathrm{O}$ product by the combustion and present in the recirculated gases. The mass fraction of each species initially present in the cylinder is thus given by

$$
x_{i}^{i v c}=x_{i}^{a i r}\left(1-F_{1}\right)+x_{i}^{b} F_{1},
$$


where $x_{i}^{a i r}$ and $x_{i}^{b}$ are the mass fractions of a species $i$ in fresh air and burned gases, respectively. $F_{1}$ is the intake BGR defined as

$$
F_{1}=1-\frac{m_{a i r, 1}}{m_{1}},
$$

where $m_{1}$ and $m_{\text {air }, 1}$ are the total mass of gas and the mass of air in the intake plenum, respectively. Assuming a local stoichimetric AFR in the burned gases, the initial mass fractions of the species are given by

$$
\begin{gathered}
x_{O_{2}}^{i v c}=x_{O_{2}}^{a i r}\left(1-F_{1}\right) \\
x_{N_{2}}^{i v c}=x_{N_{2}}^{a i r}\left(1-F_{1}\right)+\frac{k_{n, a i r}\left(y+\frac{z}{4}\right)}{\left(y+\frac{z}{4}\right) k_{n, a i r}+y+\frac{z}{2}} \frac{M_{N_{2}}}{M_{b}} F_{1} \\
x_{C O_{2}}^{i v c}=\frac{y}{\left(y+\frac{z}{4}\right) k_{n, a i r}+y+\frac{z}{2}} \frac{M_{C O_{2}}}{M_{b}} F_{1}
\end{gathered}
$$

and

$$
x_{H_{2} \mathrm{O}}^{i v c}=\frac{\frac{z}{2}}{\left(y+\frac{z}{4}\right) k_{n, a i r}+y+\frac{z}{2}} \frac{M_{\mathrm{H}_{2} \mathrm{O}}}{M_{b}} F_{1},
$$

where $x_{O_{2}}^{a i r}=0.23$ and $x_{N_{2}}^{a i r}=0.77$ correspond to the mass fractions of $\mathrm{O}_{2}$ and $\mathrm{N}_{2}$ in fresh air, respectively. $k_{n, \text { air }}=\frac{X_{N_{2}}^{\text {air }}}{X_{\mathrm{O}_{2}}^{\text {air }}}$ is the ratio between the molar fractions of $\mathrm{N}_{2}\left(X_{N_{2}}^{a i r}=0.79\right)$ and $\mathrm{O}_{2}\left(X_{O_{2}}^{a i r}=0.21\right)$ in air. $\mathrm{C}_{y} \mathrm{H}_{z}$ is the general formula for a hydrocarbon, $y$ and $z$ being the number of carbon and hydrogen atoms, respectively. $M_{i}$ is the molar mass of a species or a mixture $i$. Note that the molar masses of the aspirated gases $\left(M_{i n}\right)$ and of the burned gases $\left(M_{b}\right)$ are supposed equal to the one of air $\left(M_{\text {air }}\right)$.

\subsection{Rate Of Heat Release and mean thermodynamic conditions in the cylinder}

The second sub-model (figure 2) computes the ROHR as well as the mean thermodynamic conditions in the cylinder from the cylinder pressure $p_{c y l}$, the aspirated mass $m_{i n}$ and the injected mass $m_{f}$. 
As the combustion occurs during the closed part of the engine cycle, the ROHR is given by

$$
\frac{\delta Q_{c o m b}}{\mathrm{~d} \theta}=\frac{\delta Q_{n}}{\mathrm{~d} \theta}-\frac{\delta Q_{w}}{\mathrm{~d} \theta}
$$

The net heat release rate is calculated from the cylinder pressure using the first law of thermodynamics [13] according to

$$
\frac{\delta Q_{n}}{\mathrm{~d} \theta}=\frac{\gamma}{\gamma-1} p_{c y l} \frac{\mathrm{d} V_{c y l}}{\mathrm{~d} \theta}+\frac{1}{\gamma-1} V_{c y l} \frac{\mathrm{d} p_{c y l}}{\mathrm{~d} \theta} .
$$

The calculation of the heat transfer between the mass trapped in the cylinder and the surrounding walls only takes into account a convective contribution, the convective coefficient being modeled by the Woschni correlation [20].

The mass of fuel burned since the beginning of the combustion $m_{f, b}$ is given by

$$
m_{f, b}(\theta)=\frac{1}{Q_{l h v}} \int_{\theta_{s o c}}^{\theta} \frac{\delta Q_{c o m b}}{\mathrm{~d} \theta} \mathrm{d} \theta
$$

where $Q_{l h v}$ refers to the lower heating value of the fuel and $\theta_{s o c}$ is the value of the crank angle at the Start Of Combustion (SOC).

The mean temperature in the cylinder is obtained from the perfect gas law

$$
T_{c y l}=\frac{p_{c y l} V_{c y l}}{R n_{c y l}} .
$$

The total molar quantity of gases in the cylinder $n_{c y l}$ is assumed to be constant during the closed part of the engine cycle and equal to the sum of the molar quantity of aspirated gases and of the molar quantity of injected fuel, that is

$$
n_{c y l}=\frac{m_{i n}}{M_{i n}}+\frac{m_{f}}{M_{f}} .
$$

$M_{f}$ refers to the molar mass of the fuel.

\subsection{Thermodynamic conditions in the burned gas zone}

The third sub-model (figure 21) computes the thermodynamic conditions in the unburned and burned gases from the mass of fuel burned and from the mean thermodynamic conditions in the cylinder. In this paper, only the calculation of the burned gas temperature and of the equilibrium concentrations in the burned 
gas zone are presented since these variables constitute the main input variables of $\mathrm{NO}_{\mathrm{x}}$ formation model.

Before the SOC, the temperature in the burned gas zone $T_{b}$ is supposed to be equal to the mean cylinder temperature $T_{c y l}$. The equation describing the dynamics of the burned gas temperature after the SOC

$$
\frac{\mathrm{d}\left(n_{b} h_{n, b}\right)}{\mathrm{d} \theta}=\frac{\mathrm{d} n_{u \rightarrow b}}{\mathrm{~d} \theta} h_{n, u}+\frac{n_{b} R T_{b}}{p_{c y l}} \frac{\mathrm{d} p_{c y l}}{\mathrm{~d} \theta}+\frac{\delta Q_{w, b}}{\mathrm{~d} \theta}
$$

is obtained from the conservation of energy and takes into account energy variations due to the combustion of fuel with unburned gases, to pressure variations in the cylinder induced by the displacement of the piston, and to heat transfer at walls. $n$ and $h_{n}$ represent the molar quantity and the molar enthalpy, respectively. The molar enthalpy of the burned gases is given by

$$
h_{n, b}=\sum_{i} X_{i, b} h_{n, i}
$$

$X_{i, b}$ refers to the molar fraction of a species $i$ in the burned gas zone. The molar enthalpy $h_{n, i}$ of a species $i$ is expressed as a second-order polynomial function of the temperature [21]. Consequently, the molar enthalpy of the burned gases depends on the composition and of the temperature of the gases in the burned gas zone, so that the burned gas temperature $T_{b}$, computed from equation (15), depends on the composition of the burned gases.

The concentration of the species in the burned gases are calculated by adopting a chemical equilibrium scheme for the C-H-O-N system, using the approach proposed by Rakopoulos et al. [22]. Only eleven species are considered in the burned gases, that are the ten species $\left(\mathrm{O}_{2}, \mathrm{~N}_{2}, \mathrm{CO}_{2}, \mathrm{H}_{2} \mathrm{O}, \mathrm{H}, \mathrm{H}_{2}, \mathrm{NO}, \mathrm{O}\right.$, $\mathrm{OH}$ et $\mathrm{CO}$ ) with the highest molar fractions (between $10^{-5}$ and $10^{\circ}$ ) during the combustion 12] and the nitrogen radical $\mathrm{N}$ whose molar fraction is lower (around $10^{-8}$ ) 13] but which is involved in $\mathrm{NO}_{\mathrm{x}}$ formation. The equilibrium concentration of a species $i$ in the burned gas zone is obtained from its molar fraction $X_{i, b}$ in the burned gas zone, that is,

$$
[i]_{e q}=X_{i, b} \frac{n_{b}}{V_{b}}
$$


The molar fractions of the species in the burned gases are computed offline and are tabulated as functions of burned gas temperature and cylinder pressure according to

$$
X_{i, b}=f_{X_{i, b}}\left(T_{b}, p_{c y l}\right)
$$

\subsection{Kinetics of $\mathrm{NO}_{\mathrm{x}}$ formation}

The fourth sub-model computes $\mathrm{NO}_{\mathrm{x}}$ emissions from the thermodynamic conditions in the burned gas zone. $\mathrm{NO}_{\mathrm{x}}$ formation is modeled using the thermal mechanism which consists of three chemical reactions

$$
\begin{aligned}
& \mathrm{N}_{2}+\mathrm{O} \rightleftharpoons \mathrm{NO}+\mathrm{N} \\
& \mathrm{N}+\mathrm{O}_{2} \rightleftharpoons \mathrm{NO}+\mathrm{O} \\
& \mathrm{N}+\mathrm{OH} \rightleftharpoons \mathrm{NO}+\mathrm{H}
\end{aligned}
$$

between $\mathrm{O}_{2}, \mathrm{~N}_{2}$ and dissociations products. Under the equilibrium assumption, thermal NO formation rate can be expressed as

$$
\frac{\mathrm{d} n_{N O, c y l}}{\mathrm{~d} \theta}=\frac{1}{\omega_{e}} \frac{2 V_{b} R_{1}\left(1-\left(\frac{[\mathrm{NO}]}{[\mathrm{NO}]_{e q}}\right)^{2}\right)}{1+\frac{[\mathrm{NO}]}{[\mathrm{NO}]_{e q}} \frac{R_{1}}{R_{2}+R_{3}}}
$$

where

$$
\begin{aligned}
& R_{1}=k_{1}^{+}[\mathrm{O}]_{e q}\left[\mathrm{~N}_{2}\right]_{e q}=k_{1}^{-}[\mathrm{NO}]_{e q}[\mathrm{~N}]_{e q} \\
& R_{2}=k_{2}^{+}[\mathrm{N}]_{e q}\left[\mathrm{O}_{2}\right]_{e q}=k_{2}^{-}[\mathrm{NO}]_{e q}[\mathrm{O}]_{e q} \\
& R_{3}=k_{3}^{+}[\mathrm{OH}]_{e q}[\mathrm{~N}]_{e q}=k_{3}^{-}[\mathrm{NO}]_{e q}[\mathrm{H}]_{e q}
\end{aligned}
$$

$\omega_{e}=6 N_{e}$ is the rotational speed of the engine. The kinetical constants $k_{i}$ of equations (19) to (21) are expressed according to the Arrhenius equation

$$
k_{i}=A_{i} T_{b}^{\beta_{i}} \exp \left(-\frac{E_{a_{i}}}{R T_{b}}\right) .
$$


Table 1: Coefficients of the kinetical constant of equations (19) to 21].

\begin{tabular}{|c|c|c|c|c|}
\hline \multicolumn{2}{|c|}{ Reaction } & $\begin{array}{c}A \\
\left(\mathrm{~m}^{3} / \mathrm{mol} / \mathrm{s}\right)\end{array}$ & $\begin{array}{c}\beta \\
(-)\end{array}$ & $\begin{array}{c}E_{a} \\
(\mathrm{~J} / \mathrm{mol})\end{array}$ \\
\hline \multirow{2}{*}{$(19)$} & production & $7.6 \cdot 10^{7}$ & 0 & 315950 \\
\cline { 2 - 5 } & dissociation & $1.6 \cdot 10^{7}$ & 0 & 0 \\
\hline \multirow{2}{*}{$(20)$} & production & $6.4 \cdot 10^{3}$ & 1 & 26200 \\
\cline { 2 - 5 } & dissociation & $1.5 \cdot 10^{3}$ & 1 & 162100 \\
\cline { 2 - 6 } & production & $1 \cdot 10^{8}$ & 0 & 0 \\
\hline & dissociation & $2.0 \cdot 10^{8}$ & 0 & 196600 \\
\hline
\end{tabular}

The values of the pre-exponential factors $A_{i}$, of the exponents $\beta_{i}$ and of the energies of activation $E_{a, i}$ provided by Bowman [23] are summarized in table 1.

The evolution of $\mathrm{NO}_{\mathrm{x}}$ molar quantity, which is supposed equal to NO molar quantity, is computed from NO formation rate according to

$$
n_{N O_{x}, c y l}(\theta)=n_{N O, c y l}(\theta)=\int_{\theta_{s o c}}^{\theta} \frac{\mathrm{d} n_{N O, c y l}}{\mathrm{~d} \theta} \mathrm{d} \theta .
$$

$\mathrm{NO}_{\mathrm{x}}$ molar fraction in the cylinder exhaust is then calculated from $\mathrm{NO}_{\mathrm{x}}$ molar quantity achieved at EVO

$$
X_{N O_{x}}=\frac{n_{N O_{x}, c y l}\left(\theta_{\text {evo }}\right)}{n_{c y l}}
$$

\subsection{Results and discussion}

The results obtained with the model are compared with experimental data measured in a two-liter, four-cylinder, four-stroke, direct-injection diesel engine (engine A presented in Appendix A). The model has only physical parameters such as physical constants (universal gas constant $R$, etc.), parameters used to compute the kinetical constants of $\mathrm{NO}_{\mathrm{x}}$ formation, etc.. Only the geometrical parameters (cylinder displacement, stroke, etc.) are adapted to the considered 
engine. The experimental data set is composed of around 500 steady-state operating points corresponding to the nominal operating points used for the engine calibration, and to engine setting variations (SOC and BGR). Only the engineout $\mathrm{NO}_{\mathrm{x}}$ emissions are measured since the evolution of $\mathrm{NO}_{\mathrm{x}}$ concentration during the engine cycle is not available. A detailed description of the experimental setup and of the measurement procedure is given in Appendix A

The evolution of cylinder pressure, temperature in each zone and $\mathrm{NO}_{\mathrm{x}}$ molar fraction during an engine cycle are represented in figure 3 . The energy released by the combustion leads to an important increase in the cylinder pressure (figure $3 \mathrm{a}$ ) and in the mean cylinder temperature (figure $3 \mathrm{~b}$ ). The temperature in the burned gas zone increases suddenly at the SOC and is much higher than the mean cylinder temperature (figure 3b). In particular, the burned gas temperature exceeds the activation temperatures of $\mathrm{NO}_{\mathrm{x}}$ formation reactions (around $2200 \mathrm{~K}$ ) at the beginning of the combustion (from $\theta=362$ to 395 deg for the case shown in figure 31), so that $\mathrm{NO}_{\mathrm{x}}$ are mainly produced during this phase (figure 3c).

As the evolution of $\mathrm{NO}_{\mathrm{x}}$ concentration is not measured during the engine cycle, the estimated $\mathrm{NO}_{\mathrm{x}}$ molar fraction $X_{N O_{x}}^{e s t}$ in the cylinder exhaust is compared to the measured value $X_{N O_{x}}^{m e s}$ for each operating point. The model reproduced the decrease in $\mathrm{NO}_{\mathrm{x}}$ emissions when the BGR increases (figure 4). The Root Mean Squared Error (RMSE) and the correlation factor $r_{p}$ calculated from the Bravais-Pearson equation 24] are used for a quantitative estimation of the model accuracy. The model is unable to accurately estimate $\mathrm{NO}_{\mathrm{x}}$ emissions, the RMSE obtained for the complete data set being about $60 \%$ (figure 5 ).

The proposed model presents some drawbacks. First, it is too complex for control applications. The computations of the burned gas temperature and of the equilibrium concentrations of the species in the burned gas zone are coupled. Second, the model is unable to accurately estimate $\mathrm{NO}_{\mathrm{x}}$ emissions and has many physical parameters but no parameter to tune to fit with experimental data. However, this model has enabled to highlight the huge sensitivity of $\mathrm{NO}_{\mathrm{x}}$ emissions to the burned gas temperature, also shown by Bowman [23] and 


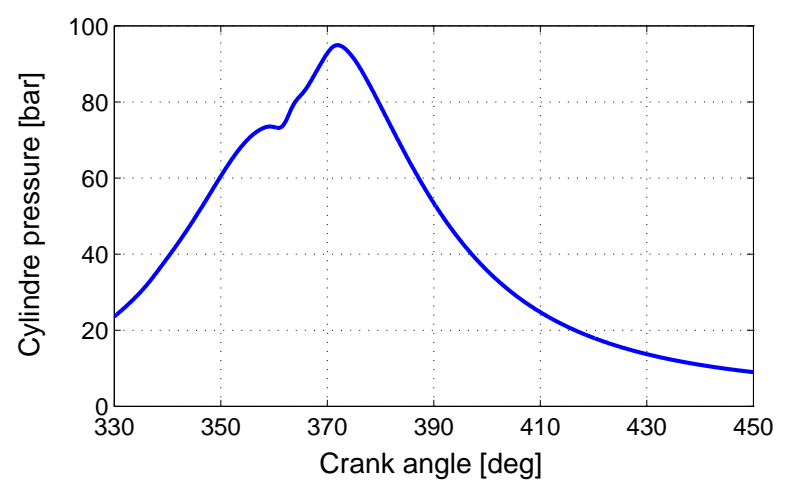

(a) Cylinder pressure

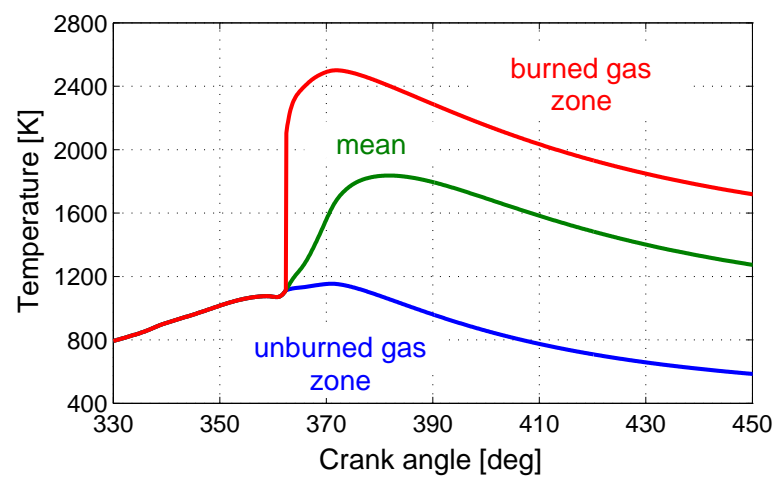

(b) Temperature

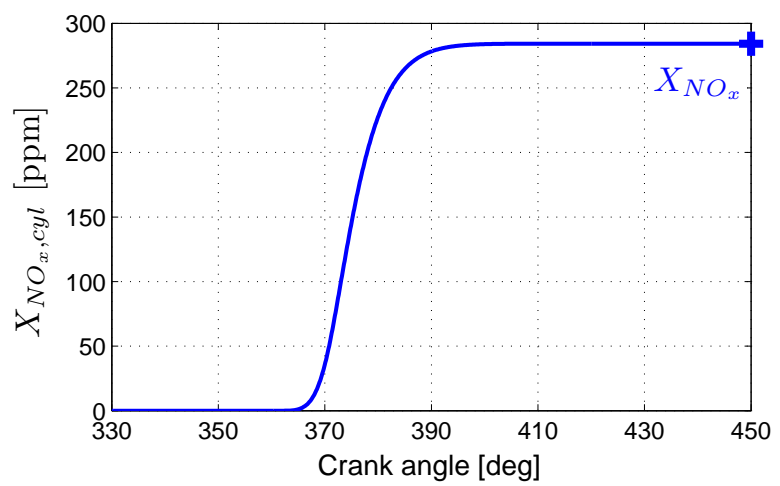

(c) $\mathrm{NO}_{\mathrm{x}}$ molar fraction

Figure 3: Evolution of cylinder pressure, temperature in each zone and $\mathrm{NO}_{\mathrm{x}}$ molar fraction during an engine cycle. Operating conditions: $N_{e}=2000 \mathrm{rpm}$; IMEP $=10$ bar; $F_{1}=12 \%$; $\theta_{\text {soc }}=362 \mathrm{deg}$. 


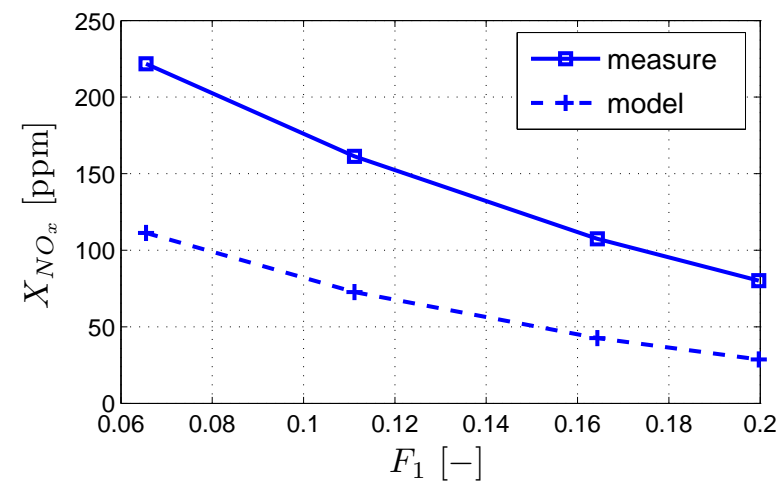

Figure 4: Comparison of estimated and measured $\mathrm{NO}_{\mathrm{x}}$ molar fraction for a variation of the BGR. Operating conditions: $N_{e}=2750 \mathrm{rpm} ; \mathrm{IMEP}=7 \mathrm{bar} ; \theta_{\text {soc }}=368 \mathrm{deg}$.

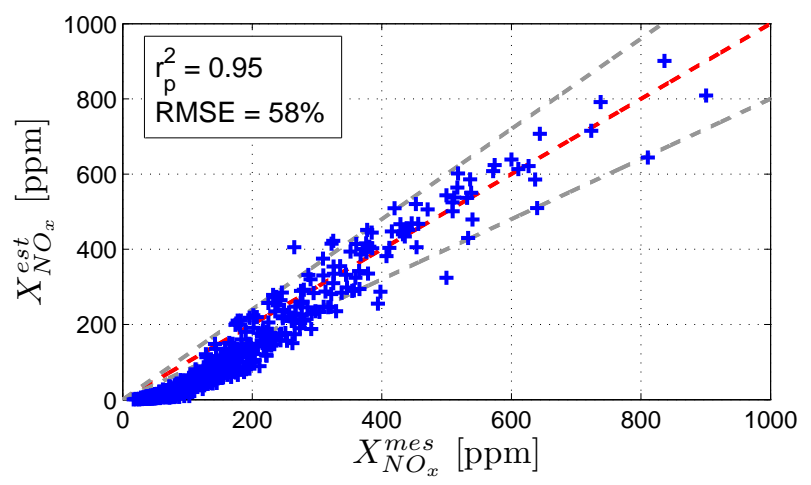

Figure 5: $\mathrm{NO}_{\mathrm{x}}$ molar fraction estimated with the reference model versus experimental data. The red dotted line represents the first bisector of the plan. The grey dotted lines represent the lines of equations $y=1.2 x$ and $y=0.8 x$ corresponding to an error of $\pm 20 \%$ on $\mathrm{NO}_{\mathrm{x}}$ emissions. 
Heywood [13]. This high sensitivity is illustrated in figure [6 where a variation of the burned gas temperature of $200 \mathrm{~K}$ leads to a huge variation of $\mathrm{NO}_{\mathrm{x}}$ molar fraction of about $1000 \mathrm{ppm}$.

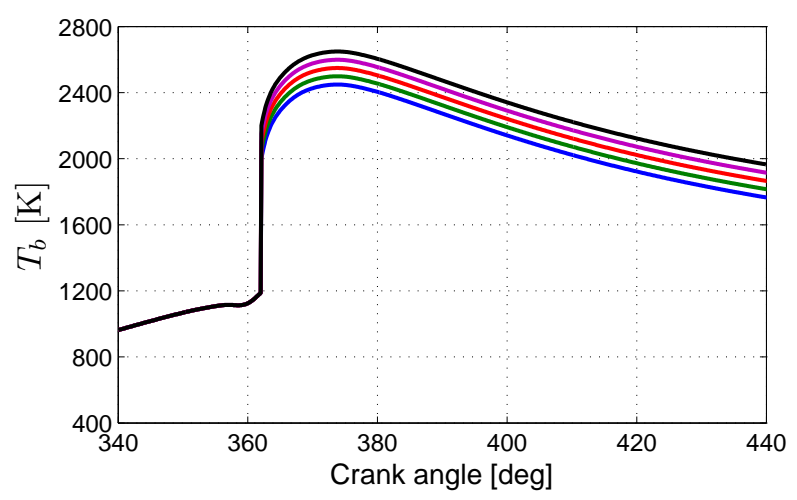

(a) Temperature

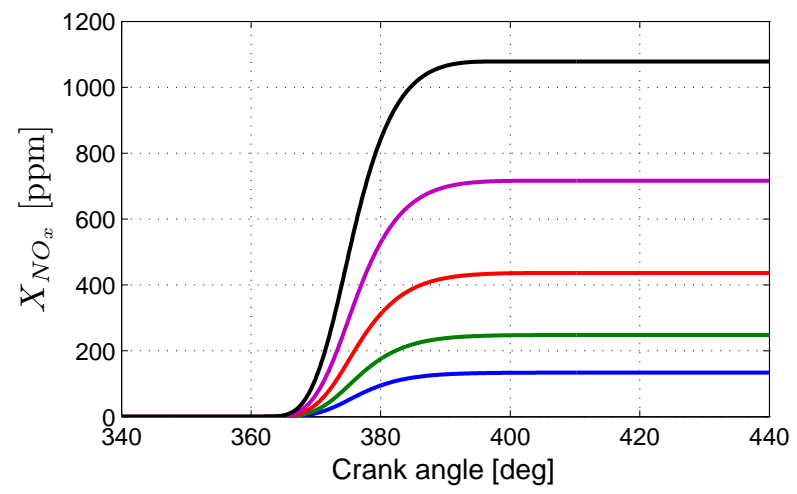

(b) $\mathrm{NO}_{\mathrm{x}}$ molar fraction

Figure 6: Illustration of $\mathrm{NO}_{\mathrm{x}}$ sensitivity to the burned gas temperature.

\section{Simplification of the crank-angle based model to a mean-value NOx model}

In this section, a mean-value $\mathrm{NO}_{\mathrm{x}}$ model is derived from the reference model. This simplification is realized in two steps.

In the first step, an adaptation of the reference model is proposed to overcome its limits (section 3.1). Since the burned gas temperature has a major 
impact on $\mathrm{NO}_{\mathrm{x}}$ emissions, we propose to introduce a new burned gas temperature model with a limited number of tunable parameters to fit with experimental data. The evolution of the burned gas temperature obtained with the reference model is shown in figure 7 the burned gas temperature increases suddenly at the SOC and then, increases more slowly during a few degrees before undergoing a relaxation during the expansion phase. This evolution is approximated by considering an instantaneous increase in temperature at the SOC to the maximum burned gas temperature $\widehat{T}_{b}$ followed by a temperature relaxation from the maximum temperature to the mean cylinder temperature $T_{c y l}$ (figure 7 ).

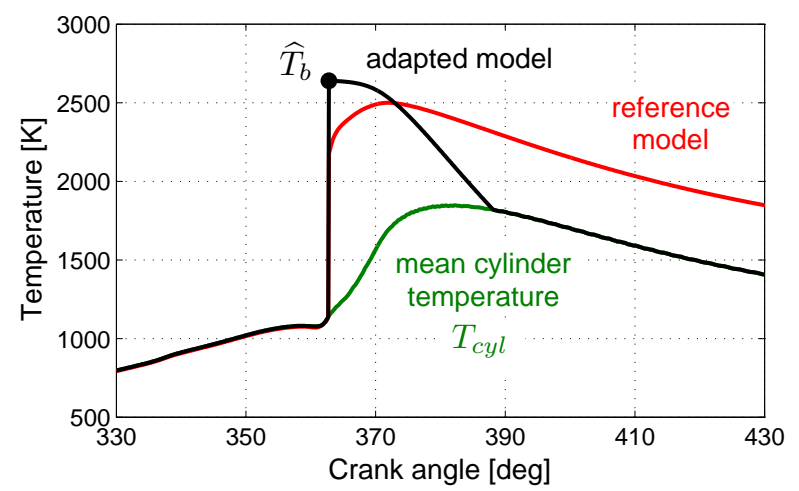

Figure 7: Evolution of the burned gas temperature estimated with the reference model and with the adapted model.

The idea is to replace the Ordinary Differential Equation (ODE) (15) describing the burned gas temperature dynamics by a static model. We search to introduce a model composed of a discrete variable that enables to decouple $\mathrm{NO}_{\mathrm{x}}$ emissions from the first-order input variables, and of a model describing the temperature relaxation from the temperature achieved at the SOC. $\mathrm{NO}_{\mathrm{x}}$ formation mainly occurs at the beginning of the combustion, when the burned gas temperature achieves its highest values. Added to the high dependency of $\mathrm{NO}_{\mathrm{x}}$ formation rate to the temperature, it leads us to consider the maximum burned gas temperature $\widehat{T}_{b}$ as the discrete variable that drives $\mathrm{NO}_{\mathrm{x}}$ production. Figure 8 represents the evolution of $\mathrm{NO}_{\mathrm{x}}$ molar fraction $X_{N O_{x}}$ versus $\widehat{T}_{b}$ 
when two main input variables (BGR and SOC) vary for a given speed $\left(N_{e}=\right.$ $2500 \mathrm{rpm})$ and a given torque (IMEP $=10 \mathrm{bar}$ ) of the engine. Note that similar trends can be observed for other values of the engine speed and torque. The evolution of $\mathrm{NO}_{\mathrm{x}}$ molar fraction with $\widehat{T}_{b}$ is the same whatever the values of the BGR and of the SOC. This discrete temperature variable is thus adapted to our problem.

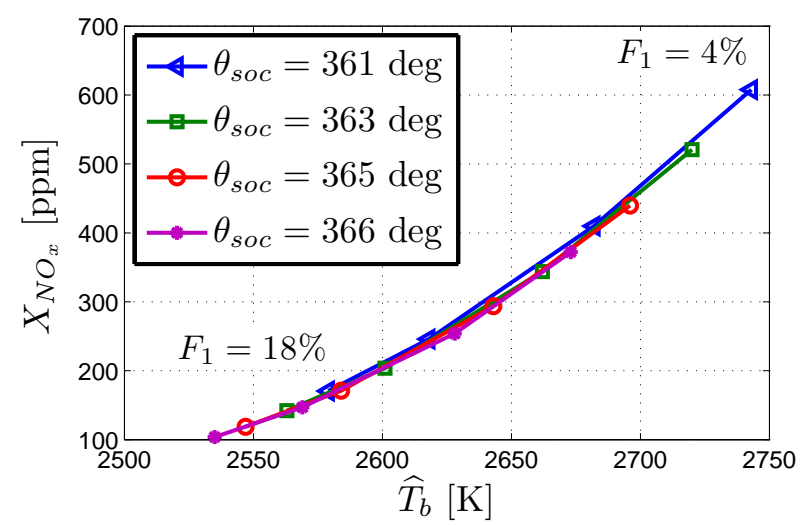

(a)

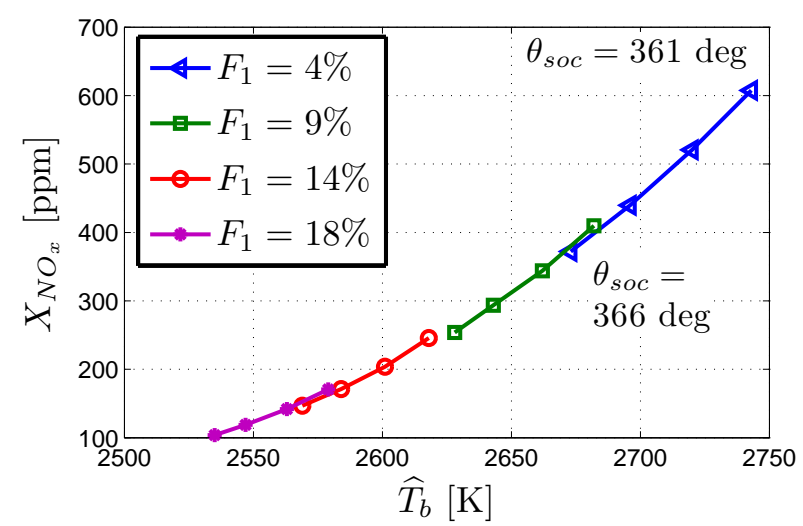

(b)

Figure 8: Evolution of $\mathrm{NO}_{\mathrm{x}}$ molar fraction versus the maximum burned gaz temperature $\widehat{T}_{b}$, when $F_{1}$ varies for four values of $\theta_{\text {soc }}$ (a) and when $\theta_{\text {soc }}$ varies for four values of $F_{1}$ (b). Operating conditions: $N_{e}=2500 \mathrm{rpm}$; IMEP $=10$ bar. 
The second step consists in simplifying the crank-angle based $\mathrm{NO}_{\mathrm{x}}$ formation model based on the Zeldovich mechanism (section 2.6) in order to get a MVM that computes $\mathrm{NO}_{\mathrm{x}}$ emissions from the maximum burned gas temperature (section 3.2).

\subsection{Adaptation of the burned gas temperature model}

The proposed static model for the burned gas temperature is adapted from the one developed by Heider [25]. The expression of the burned gas temperature is given by [18, 19]

$$
T_{b}(\theta)=\max \left(\widehat{T}_{b}\left(1-\frac{\int_{\theta_{s o c}}^{\theta}\left(p_{c y l}(\theta)-p_{m}(\theta)\right) m_{b}(\theta) \mathrm{d} \theta}{\int_{\theta_{s o c}}^{\theta_{e o c}}\left(p_{c y l}(\theta)-p_{m}(\theta)\right) m_{b}(\theta) \mathrm{d} \theta}\right), T_{c y l}(\theta)\right)
$$

where $p_{m}$ stands for the motored pressure.

The burned gas temperature is identified so that $\mathrm{NO}_{\mathrm{x}}$ emissions estimated using the Zeldovich mechanism correspond to the experimental values. The maximum burned gas temperature $\widehat{T}_{b}$ is considered as a tunable parameter. For each operating point, the value of $\widehat{T}_{b}$ is identified by minimizing the error

$$
\epsilon=\left\|X_{N O_{x}}^{e s t}-X_{N O_{x}}^{m e s}\right\|
$$

between the estimated $\mathrm{NO}_{\mathrm{x}}$ molar fraction $X_{N O_{x}}^{\text {est }}$ (equation (26) $)$ and the measured one $X_{N O_{x}}^{m e s}$ (figure 91).

\subsubsection{MVM for the maximum burned gas temperature}

A setpoint-relative model is then introduced to estimate the maximum burned gas temperature, according to

$$
\widehat{T}_{b}=\widehat{T}_{b}^{s s}\left(N_{e}, m_{f}\right)+\Delta \widehat{T}_{b}
$$

A static map $\widehat{T}_{b}^{s s}$ is thus employed to compute $\widehat{T}_{b}$ in nominal operating conditions from engine speed and injected fuel mass. This term enables to accounts for engine calibration. In order to take into account the temperature variations 


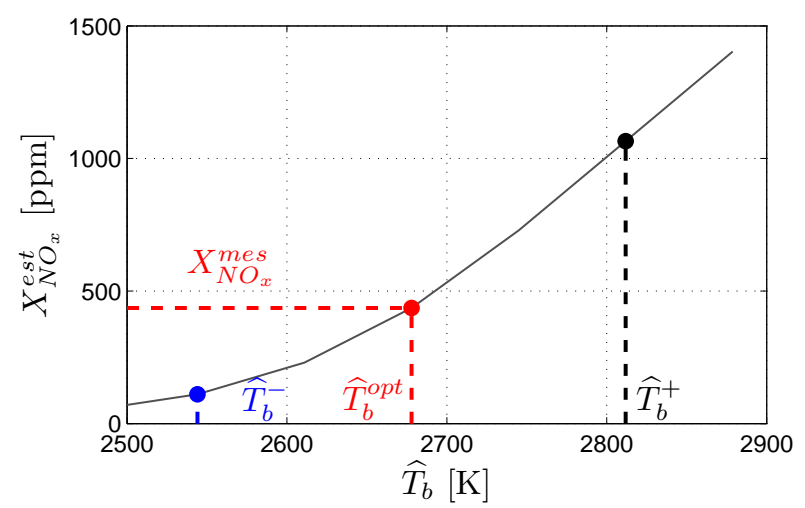

Figure 9: Methodology of burned gas temperature identification.

caused by air path and combustion phasing errors during transient operations, a correction term $\Delta \widehat{T}_{b}$ is introduced.

We search to express the correction term $\Delta \widehat{T}_{b}$ as a function of the first-order input variables impacting $\mathrm{NO}_{\mathrm{x}}$ emissions. The choice of these input variables is based on a deterministic sensitivity analysis of $\mathrm{NO}_{\mathrm{x}}$ emissions to thermodynamic conditions in intake manifold (intake pressure $p_{1}$ and BGR $F_{1}$ ), to the SOC $\theta_{\text {soc }}$ and to injection settings (injection pressure $p_{f}$; injected fuel mass $m_{f, p i l}$ and $m_{f, p o s t}$ during pilot and post injections, respectively ; delays $T_{s, p i l}$ and $T_{s, p o s t}$ between pilot and main injections, and between main and post injections, respectively). The vector $u$ of input variables is

$$
u=\left(F_{1}, p_{1}, \theta_{s o c}, p_{f}, m_{f, p i l}, m_{f, p o s t}, T_{s, p i l}, T_{s, p o s t}\right)^{T}
$$

The method employed consists in three steps. The first step consists in determining the amplitude of each input variation depending on the phenomena we want to describe: for instance, an amplitude representative of a BGR error during transient operations is considered for $F_{1}$. The amplitudes considered in this study are summarized in table 2. In the second step, experimental mono-parametric variations of each input are realized for given engine speed and torque setpoint. The third step consists in determining the sensitivity of 
the output to each input, which corresponds to the variation $\Delta X_{N O_{x}}^{i}$ of $\mathrm{NO}_{\mathrm{x}}$ molar fraction obtained by varying only the input variable $u_{i}$ with an amplitude $\Delta u_{i}$. This variation $\Delta X_{N O_{x}}^{i}$ is obtained from

$$
\Delta X_{N O_{x}}^{i}=\left.\frac{\partial X_{N O_{x}}}{\partial u_{i}}\right|_{u \backslash u_{i}} \Delta u_{i}
$$

This study is performed for two operating points $\left(N_{e}=1500 \mathrm{rpm}\right.$; IMEP $=5$ bar and $N_{e}=2000 \mathrm{rpm}$; IMEP $=8$ bar). A high sensitivity of $\mathrm{NO}_{\mathrm{x}}$ emissions to $F_{1}$ is found (figure 10), as observed by Alfieri [26], Arrègle et al. [27] and Vigild et al. 28]. The variation of $\mathrm{NO}_{\mathrm{x}}$ emissions when $\theta_{\text {soc }}$ varies can also be significant depending on the operating point (figure 10b). However, with the considered amplitudes of variation of the input variables, the intake pressure $p_{1}$, the injection pressure $p_{f}$, the repartition of the injected fuel mass between the different injections and the delay between the injections are found to have only a negligible impact on $\mathrm{NO}_{\mathrm{x}}$ emissions. Consequently, we choose to consider only $F_{1}$ and $\theta_{s o c}$ as input variables and to neglect the impact of the other variables.

As a result, the maximum burned gas temperature is expressed as

$$
\widehat{T}_{b}=\widehat{T}_{b}^{s s}\left(N_{e}, m_{f}\right)+\Delta \widehat{T}_{b}\left(\Delta F_{1}, \Delta \theta_{s o c}\right)
$$

where

$$
\Delta F_{1}=F_{1}-F_{1}^{s s}\left(N_{e}, m_{f}\right)
$$

and

$$
\Delta \theta_{s o c}=\theta_{s o c}-\theta_{s o c}^{s s}\left(N_{e}, m_{f}\right),
$$

are the absolute deviations of the BGR and of the SOC from their nominal values $F_{1}^{s s}$ and $\theta_{s o c}^{s s}$, respectively. $F_{1}^{s s}$ and $\theta_{s o c}^{s s}$ are given by static maps depending on engine speed and injected fuel mass.

The expression of the correction term $\Delta \widehat{T}_{b}$ is determined by analyzing the evolution of the maximum burned gas temperature with the BGR and the SOC for given engine speeds and torques. Figure 11a represents the evolution of $\widehat{T}_{b}$ when $F_{1}$ varies at constant $\theta_{s o c}$ for four values of $\theta_{s o c}$. $\widehat{T}_{b}$ decreases when 
Table 2: Amplitudes of variation of the input variables.

\begin{tabular}{|c|c|c|}
\hline Notation & Description & $\begin{array}{c}\text { Amplitude } \\
\text { of variation }\end{array}$ \\
\hline$F_{1}$ & BGR & $10 \%$ \\
\hline$p_{1}$ & Intake pressure & $0.2 \mathrm{bar}$ \\
\hline$\theta_{\text {soc }}$ & Start of main combustion & $5 \mathrm{deg}$ \\
\hline$p_{f}$ & Injection pressure & $100 \mathrm{bar}$ \\
\hline$m_{f, p i l}$ & Injected mass (pilot injection) & $1 \mathrm{mg} / \mathrm{cp}$ \\
\hline$m_{f, p o s t}$ & Injected mass (post-injection) & $1 \mathrm{mg} / \mathrm{cp}$ \\
\hline$T_{s, p i l}$ & $\begin{array}{r}\text { Delay between pilot and } \\
\text { main injections }\end{array}$ & $100 \mu \mathrm{s}$ \\
\hline$T_{s, p o s t}$ & Delay between main and & $100 \mu \mathrm{s}$ \\
\hline
\end{tabular}

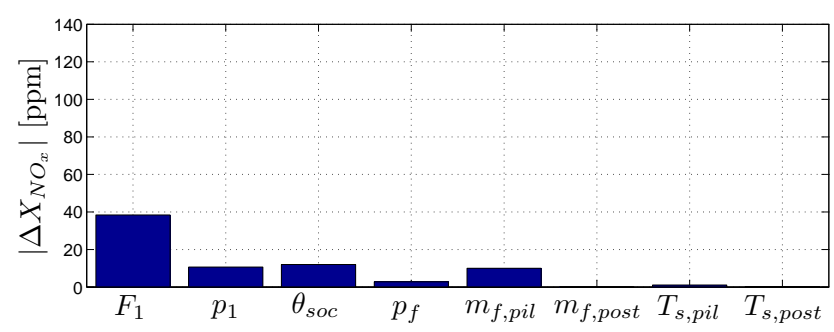

(a) $N_{e}=1500 \mathrm{rpm} ; \mathrm{IMEP}=5 \mathrm{bar}$

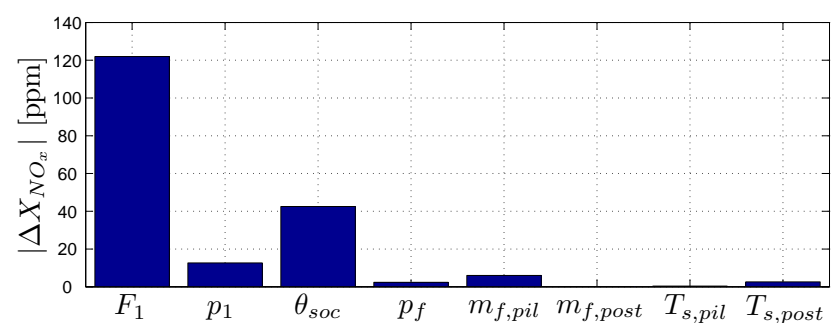

(b) $N_{e}=2000 \mathrm{rpm} ; \mathrm{IMEP}=8 \mathrm{bar}$

Figure 10: Variations of $\mathrm{NO}_{\mathrm{x}}$ emissions caused by variations of intake manifold thermodynamic conditions and of injection settings. The amplitudes of variation of input variables are given in table 2 
$F_{1}$ increases. The temperature decrease is one of the most expected effect of EGR [29, 30]: the recirculation of exhaust gases leads to an increase in the mean heat capacity of the gases present in the cylinder and tends to decrease the combustion speed. Moreover, the evolution of $\widehat{T}_{b}$ with $F_{1}$ is independent of $\theta_{\text {soc }}$. Similarly, figure $11 \mathrm{~b}$ represents the evolution of $\widehat{T}_{b}$ when $\theta_{\text {soc }}$ varies at constant $F_{1}$ for four values of $F_{1}$. $\widehat{T}_{b}$ decreases when $\theta_{\text {soc }}$ increases (delayed start of combustion). Moreover, the evolution of $\widehat{T}_{b}$ with $\theta_{\text {soc }}$ does not depend on $F_{1}$. These properties, that can be observed for other values of engine speed and torque, enable to build a model for the variation of the maximum burned gas temperature composed of two separated terms depending on variations of the $\operatorname{BGR}\left(\Delta F_{1}\right)$ and of the $\operatorname{SOC}\left(\Delta \theta_{s o c}\right)$, that is

$$
\Delta \widehat{T}_{b}=\mu_{F_{1}} \Delta F_{1}+\mu_{\text {soc }} \Delta \theta_{\text {soc }}
$$

Moreover, the evolutions of $\widehat{T}_{b}$ with $F_{1}$ and $\theta_{\text {soc }}$ can be supposed affine, so that $\Delta \widehat{T}_{b}$ is approximated by a first-order limited development on BGR and SOC variations. The expression (32) of the maximum burned gas temperature thus becomes

$$
\widehat{T}_{b}=\widehat{T}_{b}^{s s}\left(N_{e}, m_{f}\right)+\underbrace{\left.\frac{\partial \widehat{T}_{b}}{\partial F_{1}}\right|_{\theta_{s o c}}}_{\mu_{F_{1}}} \Delta F_{1}+\underbrace{\left.\frac{\partial \widehat{T}_{b}}{\partial \theta_{\text {soc }}}\right|_{F_{1}}}_{\mu_{\text {soc }}} \Delta \theta_{\text {soc }} .
$$

\subsubsection{Identification}

The identification of the model for the burned gas temperature consists in building the three static maps for the maximum burned gas temperature $\widehat{T}_{b}^{s s}$, the BGR $F_{1}^{s s}$ and the SOC $\theta_{s o c}$, as well as to identify two sensitivity functions

$$
\mu_{F_{1}}=\left.\frac{\partial \widehat{T}_{b}}{\partial F_{1}}\right|_{\theta_{s o c}}<0
$$

and

$$
\mu_{s o c}=\left.\frac{\partial \widehat{T}_{b}}{\partial \theta_{s o c}}\right|_{F_{1}}<0
$$




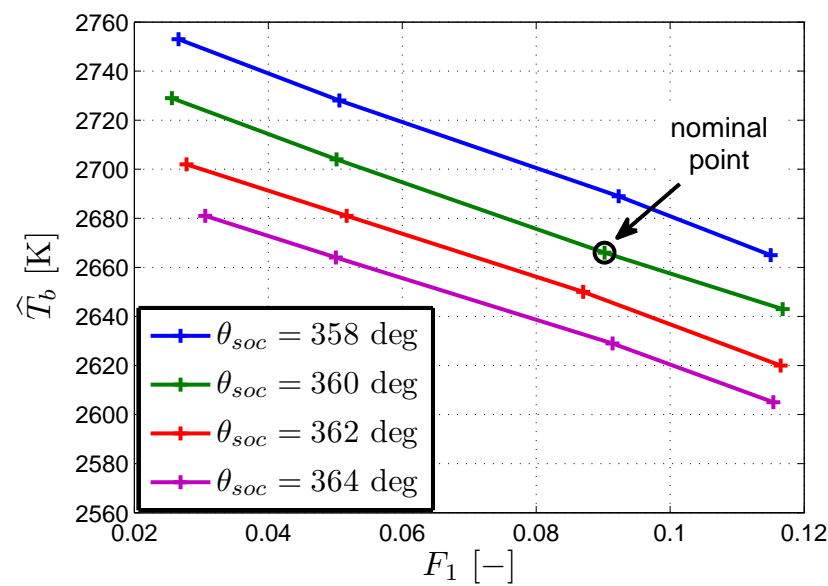

(a)

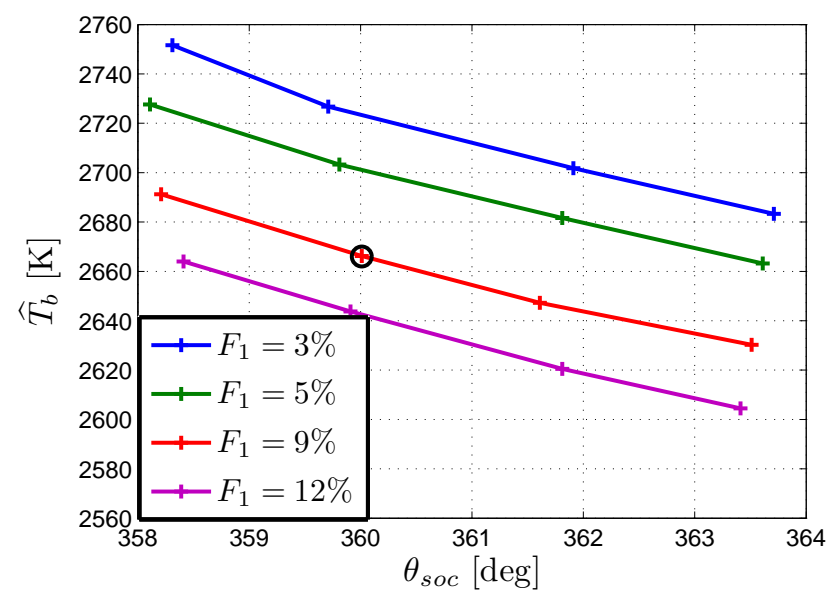

(b)

Figure 11: Sensitivity of the maximum burned gas temperature to the BGR and the SOC: evolution of $\widehat{T}_{b}$ versus $F_{1}$ for four values of $\theta_{s o c}$ (a) and versus $\theta_{s o c}$ for four values of $F_{1}$ (b). Operating conditions: $N_{e}=3500 \mathrm{rpm} ; \mathrm{IMEP}=10$ bar. 
representing the sensitivity of the maximum burned gas temperature to the BGR and to the SOC, respectively.

The static maps depending on engine speed and injected fuel mass are built from experimental data measured in nominal operating conditions tested during the engine calibration phase, so that it does not require any specific tests. The sensitivity functions $\mu_{F_{1}}$ and $\mu_{s o c}$ are identified from experimental data measured for mono-parametric variations of the BGR and of the SOC. Figure 12 represents the evolution of the maximum burned gas temperature versus the BGR for five operating points defined by the engine torque and the engine speed. For each operating points, the SOC remains equal to its nominal value. The derivative of the maximum burned gas temperature with respect to the BGR is almost constant whatever the engine speed and torque (figure 12b). Consequently, the sensitivity of the maximum burned gas temperature to the BGR is supposed to be constant and it is defined by only one parameter, that is

$$
\mu_{F_{1}}=\mu_{F_{1}, 0} .
$$

Figure 13 represents the evolution of the maximum burned gas temperature versus the SOC for five operating points defined by the engine torque and the engine speed. For each operating points, the BGR remains equal to its nominal value. The derivative of the maximum burned gas temperature with respect to the SOC tends to decrease when the nominal value of the SOC increases (figure 13b) and we choose to approximate it by an affine function of $\theta_{s o c}^{s s}$, according to

$$
\mu_{s o c}=\mu_{s o c, 0}+\mu_{s o c, 1} \theta_{s o c}^{s s} .
$$

The values of the parameters $\mu_{F_{1}}, \mu_{s o c, 1}$ and $\mu_{s o c, 0}$ identified for two diesel engines are summarized in table 3 .

\subsubsection{Results}

The proposed model of the burned gas temperature is integrated in the physical model presented in section 2. $\mathrm{NO}_{\mathrm{x}}$ emissions estimated with the adapted 


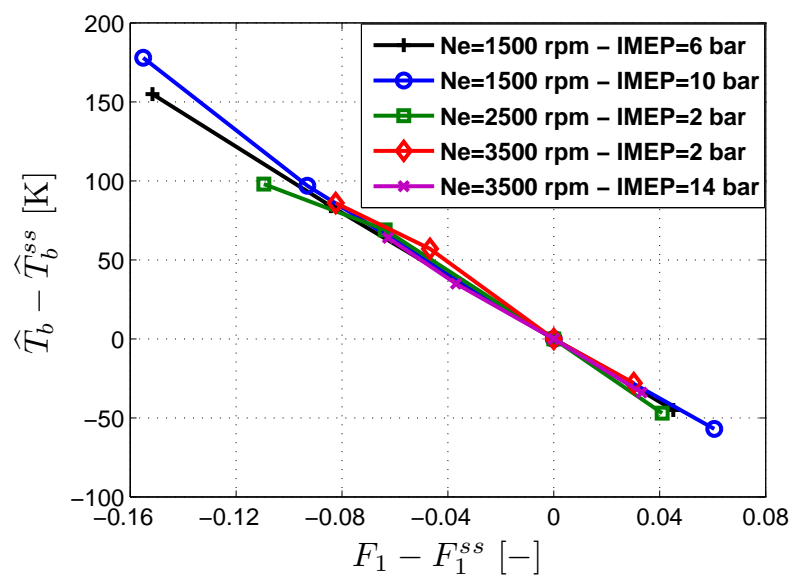

(a)

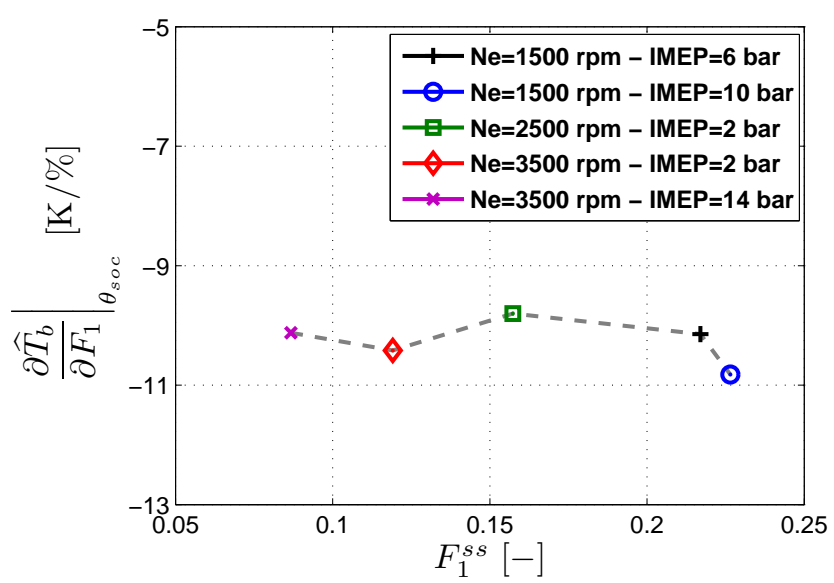

(b)

Figure 12: Sensitivity of the maximum burned gas temperature to the BGR for five operating points: variation of $\widehat{T}_{b}$ when $F_{1}$ varies (a); derivative of $\widehat{T}_{b}$ with respect to $F_{1}$ for a given $\theta_{\text {soc }}$ (b). 


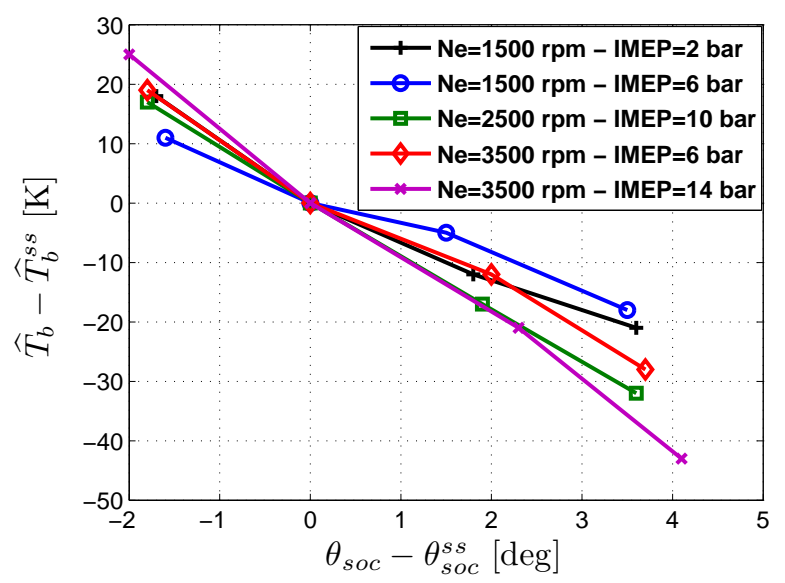

(a)

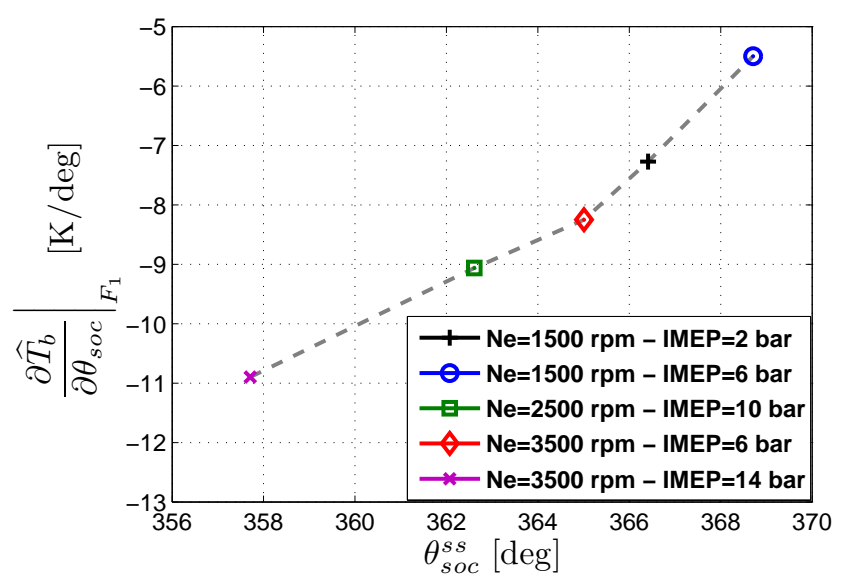

(b)

Figure 13: Sensitivity of the maximum burned gas temperature to the BGR for five operating points: variation of $\widehat{T}_{b}$ when $\theta_{\text {soc }}$ varies (a); derivative of $\widehat{T}_{b}$ with respect to $\theta_{\text {soc }}$ for a given $F_{1}(\mathrm{~b})$. 
Table 3: Parameters of the mean-value $\mathrm{NO}_{\mathrm{x}}$ model composed of the maximum burned gas temperature model and of the mean-value $\mathrm{NO}_{\mathrm{x}}$ formation model.

\begin{tabular}{|c|c|c|c|c|}
\hline Parameter & Unit & Description & Engine A & Engine B \\
\hline$\mu_{F_{1}, 0}$ & $\mathrm{~K} / \%$ & $\begin{array}{l}\text { Sensitivity } \\
\text { of } \widehat{T}_{b} \text { to } F_{1}\end{array}$ & -10.5 & -8.3 \\
\hline$\mu_{\text {soc }, 1}$ & $\mathrm{~K} / \operatorname{deg}^{2}$ & \multirow{2}{*}{$\begin{array}{l}\text { Sensitivity } \\
\text { of } \widehat{T}_{b} \text { to } \theta_{s o c}\end{array}$} & 0.67 & 1.26 \\
\hline$\mu_{\text {soc }, 0}$ & $\mathrm{~K} / \operatorname{deg}$ & & -252 & -465 \\
\hline$C_{\mathcal{M}_{1}}$ & $\mathrm{~J} / \mathrm{mol}$ & $\begin{array}{l}\text { Sensitivity of } \\
X_{N O_{x}} \text { to } \widehat{T}_{b}\end{array}$ & 502600 & 510200 \\
\hline
\end{tabular}

reference model are compared with the experimental data for the same data set as the one used in section 2.7 to validate the reference model (figure 14). The introduction of a new burned gas temperature model enables to greatly improve the accuracy of the complete model by adding three tunable parameters: while the RMSE is about $60 \%$ with the reference model (section 2), it is around $10 \%$ with the adapted model. Note that a similar accuracy is achieved using the data set obtained on engine B and that this accuracy is sufficient for engine control applications as mentioned in section 1 .

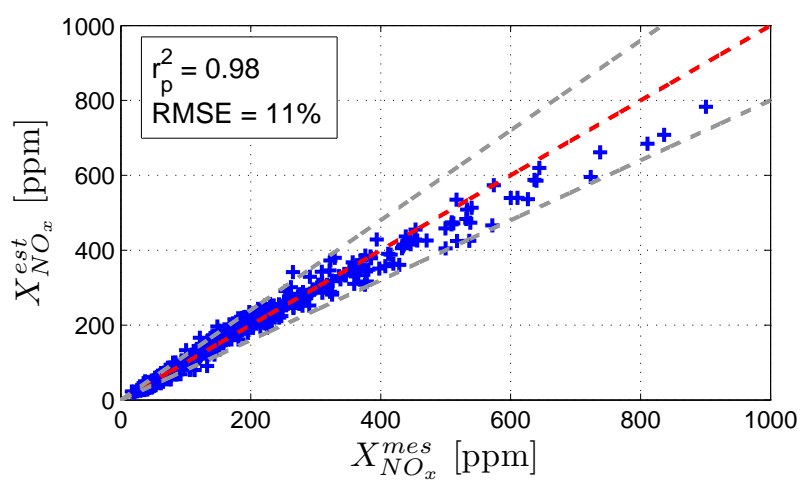

Figure 14: $\mathrm{NO}_{\mathrm{x}}$ molar fraction estimated with the adapted reference model versus experimental data (engine A). 
The ability of the model to reproduce the sensitivity of the system to BGR is also evaluated. The estimated $\mathrm{NO}_{\mathrm{x}}$ molar fraction is compared with the experimental data when the BGR varies for given engine speed and torque setpoint (figure 15a). The model reproduces the evolution of $\mathrm{NO}_{\mathrm{x}}$ emissions with the BGR. Moreover, the order of magnitude of the derivative of $\mathrm{NO}_{\mathrm{x}}$ molar fraction with respect to the BGR, estimated with the adapted reference model, corresponds to the one computed from experimental data on about fifteen operating points (figure $15 \mathrm{~b}$ ). The model is thus able to reproduce the sensitivity of the system to BGR in terms of $\mathrm{NO}_{\mathrm{x}}$ emissions.

\subsubsection{Synthesis}

In this subsection, the reference model proposed in section 2 was adapted in order to overcome its limits. A new burned gas temperature sub-model was introduced. The ODE (15) describing the dynamics of the burned gas temperature was replaced by a static model composed of a discrete variable - the maximum burned gas temperature - and of a model for the temperature relaxation (equation (27)). The maximum burned gas temperature $\widehat{T}_{b}$ is the key intermediate variable that enables to decoupled $\mathrm{NO}_{\mathrm{x}}$ emissions from the firstorder input variables (BGR and SOC). The introduction of this new burned gas temperature sub-model permitted to improve the accuracy of the complete model by adding tunable parameters. The calibration effort of the model remains limited since only three parameters are introduced, that can be identified using experimental data measured on about 100 operating points (in addition to the nominal operating points tested during the engine calibration). However, this adapted reference model is still a crank-angle based model.

\subsection{Mean-value $\mathrm{NO}_{\mathrm{x}}$ formation model}

In this subsection, the crank-angle resolved $\mathrm{NO}_{\mathrm{x}}$ formation model based on the Zeldovich mechanism is simplified to get a mean-value $\mathrm{NO}_{\mathrm{x}}$ formation model. Only discrete combustion variables are kept as input of the model: we search to compute $\mathrm{NO}_{\mathrm{x}}$ emissions from the maximum burned gas temperature and no 


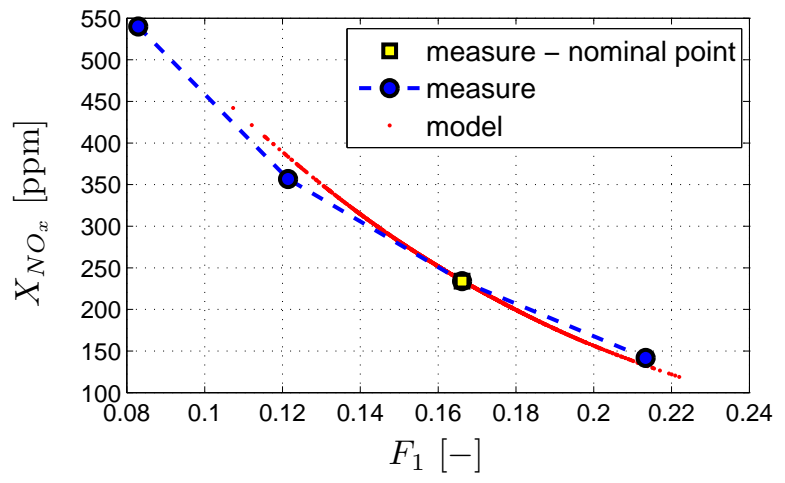

(a)

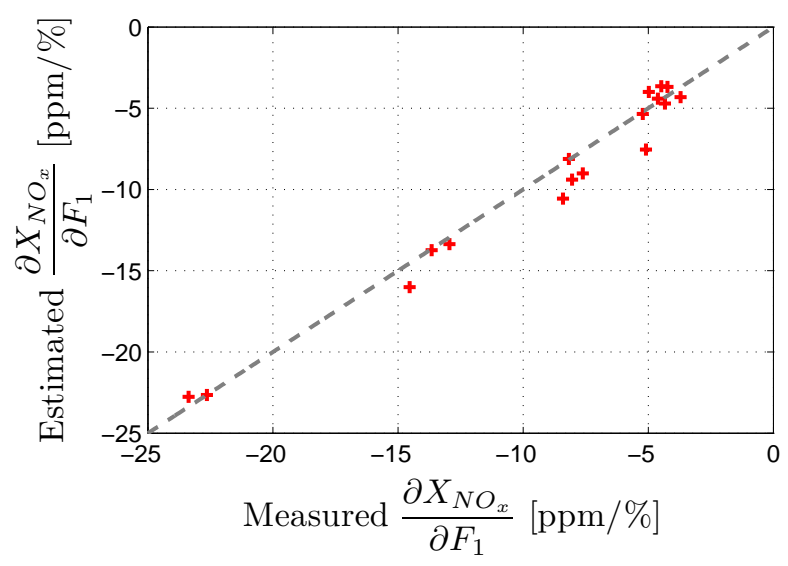

(b)

Figure 15: Comparison of estimated and measured $\mathrm{NO}_{\mathrm{x}}$ molar fraction when the BGR varies for given engine speed $\left(N_{e}=1000 \mathrm{rpm}\right.$ ) and engine torque (IMEP= $7 \mathrm{bar}$ ) (a); comparison of the derivative of $\mathrm{NO}_{\mathrm{x}}$ molar fraction as respect to the BGR, estimated with the adapted reference model, with the derivative computed from experimental data on several operating points (b) (engine A). 
more from the evolution of the burned gas temperature during the engine cycle.

With the crank-angle based model, the total quantity of $\mathrm{NO}_{\mathrm{x}}$ produced during an engine cycle (equation (25)) is calculated from the $\mathrm{NO}_{\mathrm{x}}$ formation rate modeled using the Zeldovich mechanism (equation (221)).

$\mathrm{NO}_{\mathrm{x}}$ formation rate is separated in two terms according to

$$
\frac{\mathrm{d} n_{N O_{x}, c y l}(\theta)}{\mathrm{d} \theta}=k_{N O_{x}}(\theta) g_{N O_{x}}(\theta),
$$

where

$$
k_{N O_{x}}=2 A_{1}^{+} \exp \left(-\frac{E_{a_{1}}^{+}}{R T_{b}}\right) \frac{\left(1-\left(\frac{[\mathrm{NO}]}{[\mathrm{NO}]_{e q}}\right)^{2}\right)}{1+\frac{[\mathrm{NO}]}{[\mathrm{NO}]_{e q}} \frac{R_{1}}{R_{2}+R_{3}}}
$$

is equivalent to a kinetical constant and

$$
g_{N O_{x}}=[\mathrm{O}]_{e q}\left[\mathrm{~N}_{2}\right]_{e q} V_{b} \frac{1}{\omega_{e}}
$$

depends on the equilibrium concentrations of reagent species involved in $\mathrm{NO}_{\mathrm{x}}$ formation $\left(\mathrm{N}_{2}\right.$ and $\left.\mathrm{O}\right)$.

$k_{N O_{x}}$ is then replaced by a discrete variable

$$
\overline{k_{N O_{x}}}=\frac{1}{\theta_{f}-\theta_{0}} \int_{\theta_{0}}^{\theta_{f}} k_{N O_{x}}(\theta) \mathrm{d} \theta,
$$

corresponding to the mean value of $k_{N O_{x}}$ during the phase of $\mathrm{NO}_{\mathrm{x}}$ production. $\theta_{0}$ and $\theta_{f}$ corresponds to the beginning and the end of $\mathrm{NO}_{\mathrm{x}}$ production phase. The total molar quantity of $\mathrm{NO}_{\mathrm{x}}$ produced during an engine cycle

$$
n_{N O_{x}}=\int_{\theta_{s o c}}^{\theta_{e o c}} k_{N O_{x}}(\theta) g_{N O_{x}}(\theta) \mathrm{d} \theta
$$

is thus approximated by

$$
n_{N O_{x}}=\overline{k_{N O_{x}}} \int_{\theta_{0}}^{\theta_{f}} g_{N O_{x}}(\theta) \mathrm{d} \theta .
$$

The total molar quantity of $\mathrm{NO}_{\mathrm{x}}$ computed from $\overline{k_{N O_{x}}}$ (equation (46)) is compared with the one obtained from $k_{N O_{x}}$ (equation (45)) for a data set composed 
the nominal operating points and of BGR and $\mathrm{SOC}$ variations (figure 16). $\mathrm{NO}_{\mathrm{x}}$ emissions estimated from $\overline{k_{N O_{x}}}$ present a very good correlation with the emissions estimated from $k_{N O_{x}}\left(r_{p}^{2}=1\right)$. The mean error committed on $n_{N O_{x}}$ by averaging the kinetical constant $k_{N O_{x}}$ is $0.4 \mathrm{mmol}$, that is $8 \%$ of the molar quantity estimated from $k_{N O_{x}}$.

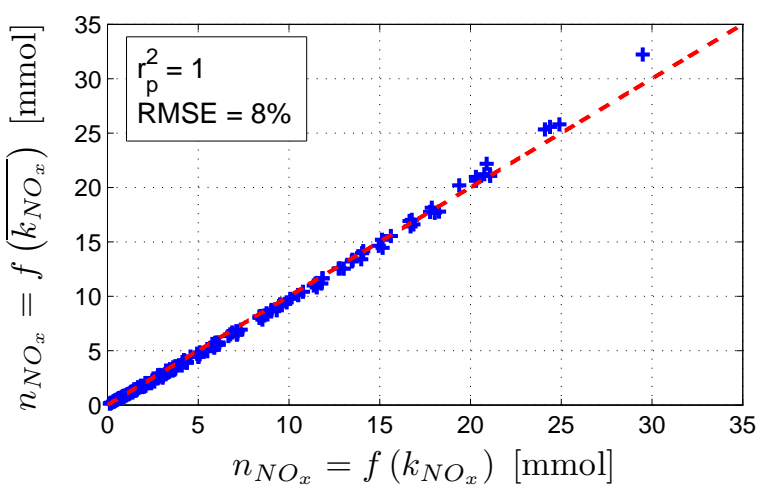

Figure 16: Comparison of the total molar quantity of $\mathrm{NO}_{\mathrm{x}}$ produced during an engine cycle computed from $\overline{k_{N O_{x}}}\left(n_{N O_{x}}=f\left(\overline{k_{N O_{x}}}\right)\right)$ with the one calculated from $k_{N O_{x}}$ $\left(n_{N O_{x}}=f\left(k_{N O_{x}}\right)\right)$.

As a result, the total molar quantity of $\mathrm{NO}_{\mathrm{x}} n_{N O_{x}}$ is expressed using two terms: $\overline{k_{N O_{x}}}$ and

$$
I_{N O_{x}}=\int_{\theta_{0}}^{\theta_{f}} g_{N O_{x}}(\theta) \mathrm{d} \theta .
$$

$I_{N O_{x}}$ corresponds to a source term and depends on equilibrium concentrations of reagents in $\mathrm{NO}_{\mathrm{x}}$ formation reactions $\left(\mathrm{O}\right.$ et $\left.\mathrm{N}_{2}\right)$. This source term is multiplied by $\overline{k_{N O_{x}}}$ which is equivalent to a kinetical constant and represents the intensity of $\mathrm{NO}_{\mathrm{x}}$ formation.

This two terms are expressed in terms of the maximum burned gas temperature $\widehat{T}_{b}$ and are identified separately from the values estimated with the adapted reference model.

The evolution of $\overline{k_{N O_{x}}}$ as a function of $\widehat{T}_{b}$ is thus analyzed for variations of 
the BGR and of the SOC. These variations are realized for several operating points defined by the engine speed and torque setpoint. For each operating point, the BGR is varied at constant SOC for four values of the SOC, and the SOC is varied at constant BGR for four values of the BGR. For given engine speed and torque setpoint, $\overline{k_{N O_{x}}}$ is strictly increasing with $\widehat{T}_{b}$ (figure 17) and its evolution is independent of $F_{1}$ and of $\theta_{s o c}$. Moreover, the evolution of $\overline{k_{N O_{x}}}$ with $\widehat{T}_{b}$ does not depend on the engine operating point either.

The logarithm of $\overline{k_{N O_{x}}}$ follows an affine evolution with respect the inverse of the maximum burned gas temperature (figure [18), so that $\overline{k_{N O_{x}}}$ is expressed as

$$
\overline{k_{N O_{x}}}=C \exp \left(-\frac{E_{a}^{\prime}}{R \widehat{T}_{b}}\right),
$$

where $C$ and $E_{a}^{\prime}$ are constants. Note that the exponential dependency of $\overline{k_{N O_{x}}}$ with the inverse of the temperature can be explained by the fact that $\overline{k_{N O_{x}}}$ is equivalent to a kinetical constant.

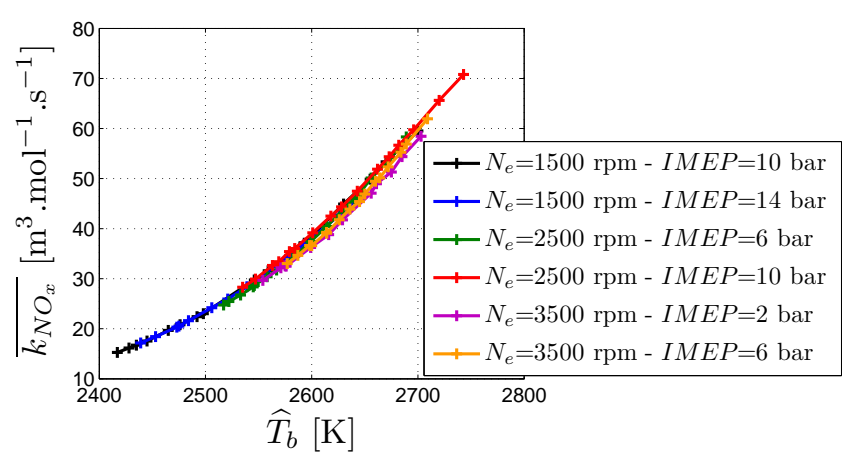

Figure 17: Evolution of $\overline{k_{N O_{x}}}$ with respect to $\widehat{T}_{b}$ when $F_{1}$ and $\theta_{s o c}$ vary for given engine speeds and torque setpoints.

In the same way, the evolution of $I_{N O_{x}}$ with $\widehat{T}_{b}$ is analyzed for BGR and SOC variations. For given engine speed and torque setpoint, $I_{N O_{x}}$ is strictly increasing with $\widehat{T}_{b}$ (figure [19) and its evolution is independent of $F_{1}$ and of $\theta_{\text {soc }}$. However, contrary to the one of $\overline{k_{N O_{x}}}$, the evolution of $I_{N O_{x}}$ with $\widehat{T}_{b}$ depends on the engine operating point. 


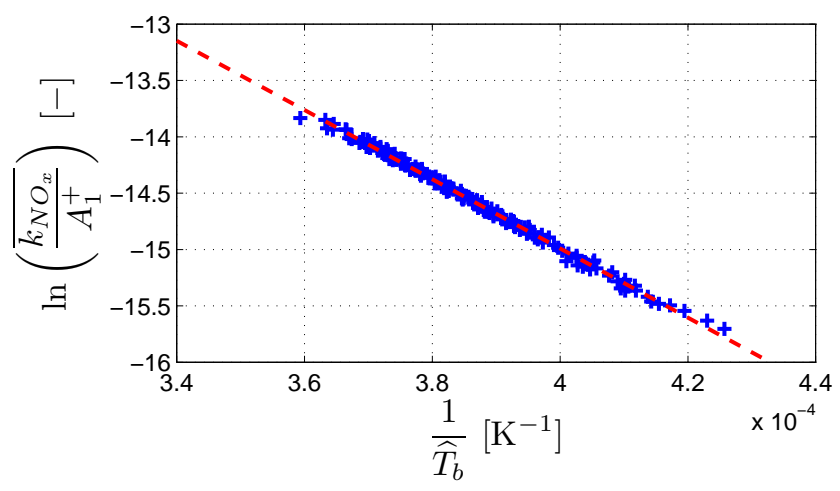

Figure 18: Evolution of $\overline{k_{N O_{x}}}$ with respect to $\widehat{T}_{b}$.

$I_{N O_{x}}$ is thus computed relatively to its nominal value $I_{N O_{x}}^{s s}$ obtained in nominal operating conditions. The logarithm of $\frac{I_{N O_{x}}}{I_{N O_{x}}^{s s}}$ follows a linear evolution with $\frac{1}{\widehat{T}_{b}}-\frac{1}{\widehat{T}_{b}^{s s}}$ (figure 20), so that $\frac{I_{N O_{x}}}{I_{N O_{x}}^{s s}}$ is expressed as

$$
\frac{I_{N O_{x}}}{I_{N O_{x}}^{s s}}=\exp \left(-\frac{E_{a}^{\prime \prime}}{R}\left(\frac{1}{\widehat{T}_{b}}-\frac{1}{\widehat{T}_{b}^{s s}}\right)\right)
$$

where $E_{a}^{\prime \prime}$ is a constant. Note that $I_{N O_{x}}$ depends on the equilibrium concentrations of $\mathrm{N}_{2}$ and $\mathrm{O}$, and thus, on equilibrium molar fractions of these species which are highly sensitive to the burned gas temperature (equation (18)), justifying the expression of $I_{N O_{x}}$ as a function of $\widehat{T}_{b}$. Moreover, $I_{N O_{x}}$ also depends on the duration of $\mathrm{NO}_{\mathrm{x}}$ formation phase, and thus, on the operating point defined by engine speed and injected fuel mass.

Consequently, the total molar quantity of $\mathrm{NO}_{\mathrm{x}}$ produced during an engine cycle, $n_{N O_{x}}=\overline{k_{N O_{x}}} I_{N O_{x}}$, is computed relatively to its nominal value $n_{N O_{x}}^{s s}=$ $\overline{k_{N O_{x}}^{s s}} I_{N O_{x}}^{s s}$. Taking into account the expressions (48) and (49) of $\overline{k_{N O_{x}}}$ and $I_{N O_{x}}$ as functions of $\widehat{T}_{b}$, the expression (46) of the total molar quantity of $\mathrm{NO}_{\mathrm{x}}$ becomes

$$
n_{N O_{x}}=n_{N O_{x}}^{s s} \exp \left(-\frac{C_{\mathcal{M}_{1}}}{R}\left(\frac{1}{\widehat{T}_{b}}-\frac{1}{\widehat{T}_{b}^{s s}}\right)\right),
$$

where $C_{\mathcal{M}_{1}}=E_{a}^{\prime}+E_{a}^{\prime \prime}$ is a constant equivalent to an activation energy. $n_{N O_{x}}^{s s}$ 


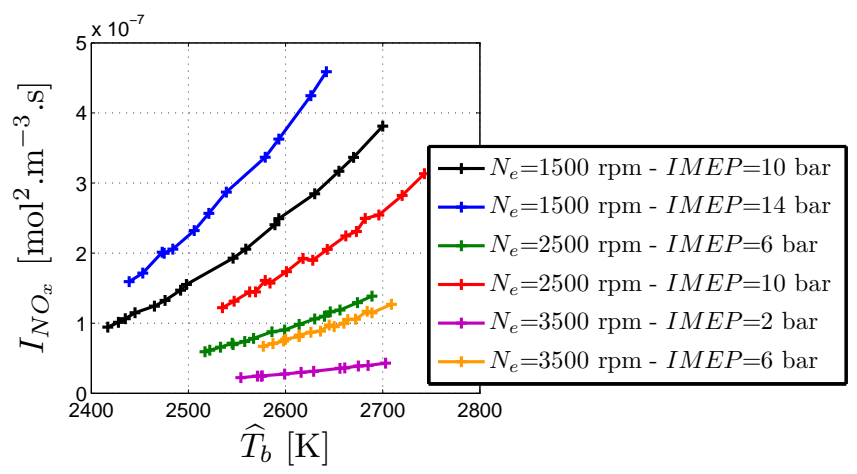

Figure 19: Evolution of $I_{N O_{x}}$ with respect to $\widehat{T}_{b}$ when $F_{1}$ and $\theta_{\text {soc }}$ vary for given engine speeds and torque setpoints.

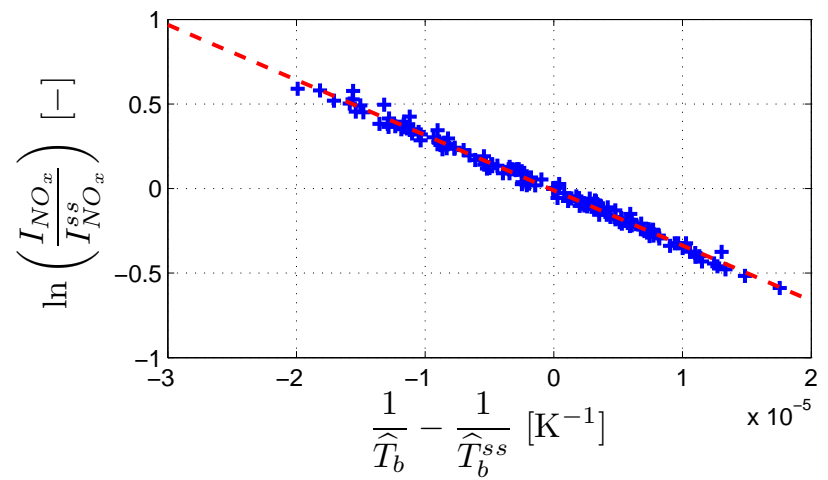

Figure 20: Evolution of $\frac{I_{N O_{x}}}{I_{N O_{x}}^{s s}}$ with respect to the maximum burned gas temperature. 
and $\widehat{T}_{b}^{s s}$ depend on engine speed and injected fuel mass.

From the total molar quantity $n_{N O_{x}}, \mathrm{NO}_{\mathrm{x}}$ molar fraction is computed according to equation (26), as a function of engine speed $N_{e}$, injected fuel mass $m_{f}$, aspirated mass $m_{i n}$ and maximum burned gas temperature $\widehat{T}_{b}$, that is

$$
X_{N O_{x}}=X_{N O_{x}}^{s s}\left(N_{e}, m_{f}\right) \frac{m_{i n}^{s s}\left(N_{e}, m_{f}\right)}{m_{i n}} \exp \left(-\frac{C_{\mathcal{M}_{1}}}{R}\left(\frac{1}{\widehat{T}_{b}}-\frac{1}{\widehat{T}_{b}^{s s}\left(N_{e}, m_{f}\right)}\right)\right) .
$$

\subsubsection{Identification}

The identification of the mean-value $\mathrm{NO}_{\mathrm{x}}$ formation model consists in building the three steady-state maps for the maximum burned gas temperature $\widehat{T}_{b}^{s s}$, the aspirated mass $m_{i n}^{s s}$ and $\mathrm{NO}_{\mathrm{x}}$ molar fraction $X_{N O_{x}}^{s s}$ and to identify the parameter $C_{\mathcal{M}_{1}}$. The steady-state maps depend on engine speed and injected fuel mass, and are built from experimental data measured in nominal operating conditions tested during the engine calibration phase. The parameter $C_{\mathcal{M}_{1}}$, which is equivalent to an activation energy and represents the sensitivity of $\mathrm{NO}_{\mathrm{x}}$ emissions to $\widehat{T}_{b}$, is identified from experimental data measured for monoparametric variations of the BGR and of the SOC. The values of the parameter $C_{\mathcal{M}_{1}}$ identified for two diesel engines are summarized in table 3

\subsection{Mean-value $\mathrm{NO}_{\mathrm{x}}$ model}

Finally, a mean-value $\mathrm{NO}_{\mathrm{x}}$ model $\mathcal{M}_{1}$ is obtained by associating the model computing the maximum burned gas temperature $\widehat{T}_{b}$ from first-order input variables (BGR and SOC) (equation (36)), with the mean-value $\mathrm{NO}_{\mathrm{x}}$ formation model calculating $\mathrm{NO}_{\mathrm{x}}$ molar fraction $X_{N O x}$ from $\widehat{T}_{b}$ (equation (51)). The structure of the model $\mathcal{M}_{1}$ is represented in figure 21.

The model takes as input the engine speed $N_{e}$, the injected fuel mass $m_{f}$, the BGR $F_{1}$, the SOC $\theta_{s o c}$ and the aspirated mass $m_{i n}$. The maximum burned gas temperature $\widehat{T}_{b}$ is the key intermediate variable that enables to decoupled $\mathrm{NO}_{\mathrm{x}}$ emissions from the first-order input variables. This model uses five static 


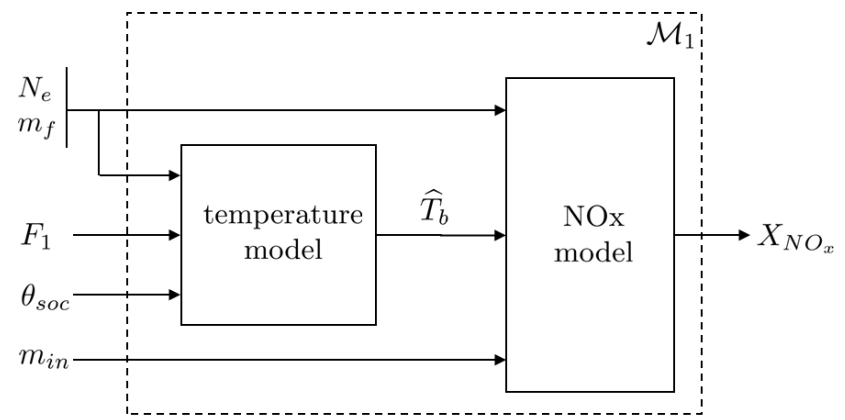

Figure 21: Structure of the mean-value $\mathrm{NO}_{\mathrm{x}}$ model $\mathcal{M}_{1}$.

maps for the BGR, the SOC, the maximum burned gas temperature, the aspirated mass and $\mathrm{NO}_{\mathrm{x}}$ molar fraction. It has four parameters that are the three parameters of the burned gas temperature model $\left(\mu_{F_{1}, 0}, \mu_{s o c, 0}\right.$ and $\left.\mu_{s o c, 1}\right)$ and the parameter $C_{\mathcal{M}_{1}}$ of the mean-value $\mathrm{NO}_{\mathrm{x}}$ formation model.

\section{Results}

This section is dedicated to the validation of the mean-value $\mathrm{NO}_{\mathrm{x}}$ model $\mathcal{M}_{1}$ in both steady-state and transient operating conditions.

\subsection{Steady-state results}

The estimated $\mathrm{NO}_{\mathrm{x}}$ emissions are compared with the experimental data for the same data set as the one used in sections 2.7 and 3.1 .3 to validate the reference and the adapted reference models (figure 22). The model estimates $\mathrm{NO}_{\mathrm{x}}$ emissions with a correct accuracy for engine control applications, the RMSE being about 10\%. A similar accuracy is achieved using the data set obtained on engine $\mathrm{B}$. Note that the mean-value $\mathrm{NO}_{\mathrm{x}}$ model presents the same accuracy as the adapted reference model despite the simplification of the $\mathrm{NO}_{\mathrm{x}}$ formation model that enables to compute $\mathrm{NO}_{\mathrm{x}}$ emissions from discrete combustion variables and no more from the evolution of the cylinder pressure during the engine cycle. Moreover, the conservation of the accuracy of the model is obtained with 


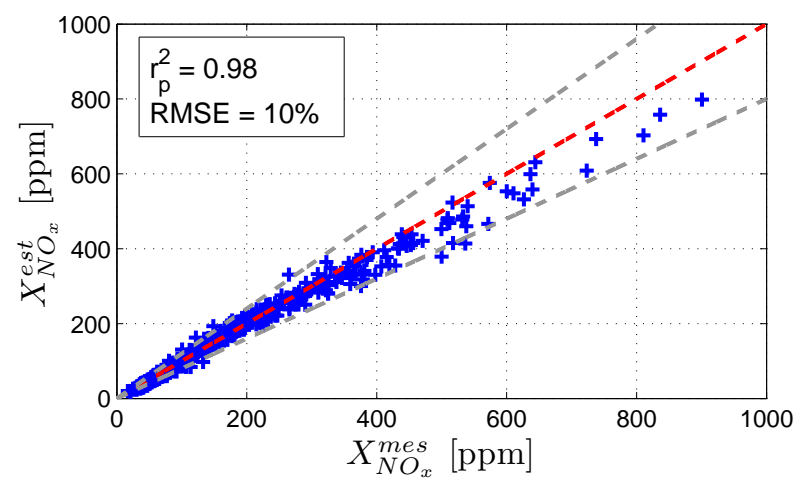

Figure 22: $\mathrm{NO}_{\mathrm{x}}$ molar fraction estimated with the mean-value $\mathrm{NO}_{\mathrm{x}}$ model versus experimental data (engine A).

only one additional parameter identified using the same experimental data as those employed for the identification of the burned gas temperature model.

The ability of the mean-value model to reproduce the sensitivity of the system to BGR is evaluated as it was done for the adapted reference model in section 3.1.3. $\mathrm{NO}_{\mathrm{x}}$ molar fractions estimated with the adapted reference model and with the mean-value $\mathrm{NO}_{\mathrm{x}}$ model are compared with the experimental data when the BGR varies for given engine speed and torque setpoint (figure 23a). Both models reproduce the evolution of $\mathrm{NO}_{\mathrm{x}}$ emissions with the BGR. Moreover, the order of magnitude of the derivatives of $\mathrm{NO}_{\mathrm{x}}$ molar fraction with respect to the BGR, estimated with the both models, corresponds to the one computed from experimental data on about fifteen operating points (figure 23b). Consequently, the MVM presents the same sensitivity to BGR as the crank-angle based model. The simplification of the adapted reference model to derive the MVM has not degraded the ability of the model to reproduce the sensitivity of the system to BGR.

\subsection{Transient results}

The ability of the mean-value $\mathrm{NO}_{\mathrm{x}}$ model to estimate $\mathrm{NO}_{\mathrm{x}}$ emissions during transient operations is evaluated on driving cycles realized on a 1.5-liter, 


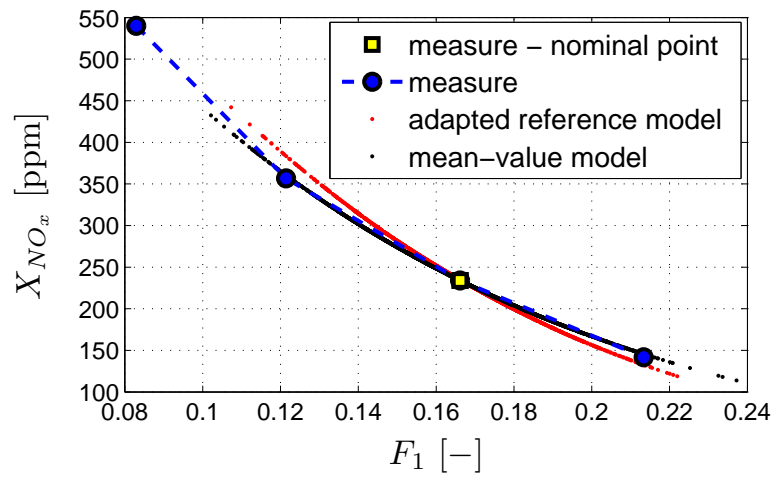

(a)

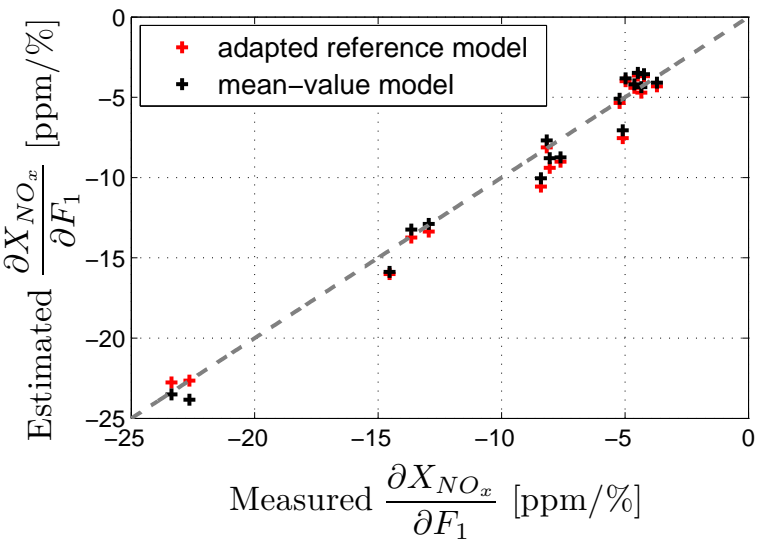

(b)

Figure 23: Comparison of estimated and measured $\mathrm{NO}_{\mathrm{x}}$ molar fraction when the $\mathrm{BGR}$ varies for given engine speed $\left(N_{e}=1000 \mathrm{rpm}\right.$ ) and engine torque (IMEP= 7 bar) (a); comparison of the derivative of $\mathrm{NO}_{\mathrm{x}}$ molar fraction as respect to the BGR, estimated with the adapted reference model and with the mean-value $\mathrm{NO}_{\mathrm{x}}$ model, with the derivative computed from experimental data on several operating points (b) (engine A). 
four-cylinder, four-stroke, direct-injection diesel engine (engine B presented in Appendix A.

The estimated and measured $\mathrm{NO}_{\mathrm{x}}$ mass flow $\dot{m}_{N O_{x}}$ are represented in figure 24 for a portion of a WLTC cycle. The BGR does not converge instantaneously to its setpoint value during transients due to the slow dynamics of the air path causes by the transportation duration of exhaust gases to the intake manifold (figure 25a). The lack of BGR leads to large overshoots in $\mathrm{NO}_{\mathrm{x}}$ emissions compared with the steady-state values given by a static map depending on engine speed and injected fuel mass (figure 25b). Note that $\mathrm{NO}_{\mathrm{x}}$ emissions are measured in the exhaust line using a HORIBA gas analyser and that the measured signal is then deconvoluated to get the signal at the cylinder exhaust. The model correctly reproduces $\mathrm{NO}_{\mathrm{x}}$ evolution during transients (figure 24d).

We also search to evaluate the capacity of the model to estimate the total mass of $\mathrm{NO}_{\mathrm{x}}$ produced during a driving cycle as well as the part of $\mathrm{NO}_{\mathrm{x}}$ emissions produced during transients. The total mass of $\mathrm{NO}_{\mathrm{x}}$ produced during a cycle is given by

$$
m_{N O_{x}}^{t o t}=\int_{t_{0}}^{t_{f}} \dot{m}_{N O_{x}}(t) \mathrm{d} t
$$

where $t_{0}$ and $t_{f}$ are the initial and final times of the driving cycle, respectively. The steady-state $\mathrm{NO}_{\mathrm{x}}$ mass is obtained from

$$
m_{N O_{x}}^{s s}=\int_{t_{0}}^{t_{f}} \dot{m}_{N O_{x}}^{s s}(t) \mathrm{d} t
$$

where the steady-state $\mathrm{NO}_{\mathrm{x}}$ mass flow

$$
\dot{m}_{N O_{x}}^{s s}=f_{N O_{x}}\left(N_{e}, m_{f}\right)
$$

is given by a static map depending on engine speed and injected fuel mass. $\mathrm{NO}_{\mathrm{x}}$ mass produced during transient operations $m_{N O_{x}}^{t}$ is defined as the difference between the total mass of $\mathrm{NO}_{\mathrm{x}} m_{N O_{x}}^{t o t}$ and the steady-state value $m_{N O_{x}}^{s s}$, so that $\mathrm{NO}_{\mathrm{x}}$ transient part is expressed as

$$
\tau_{N O_{x}}^{t}=\frac{m_{N O_{x}}^{t o t}-m_{N O_{x}}^{s s}}{m_{N O_{x}}^{t o t}}=\frac{m_{N O_{x}}^{t}}{m_{N O_{x}}^{t o t}} .
$$




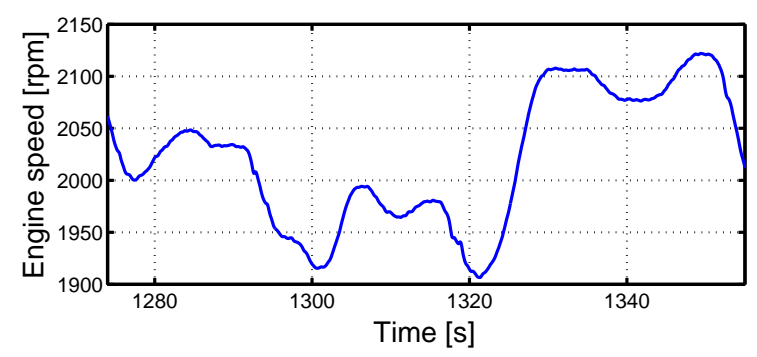

(a) Engine speed

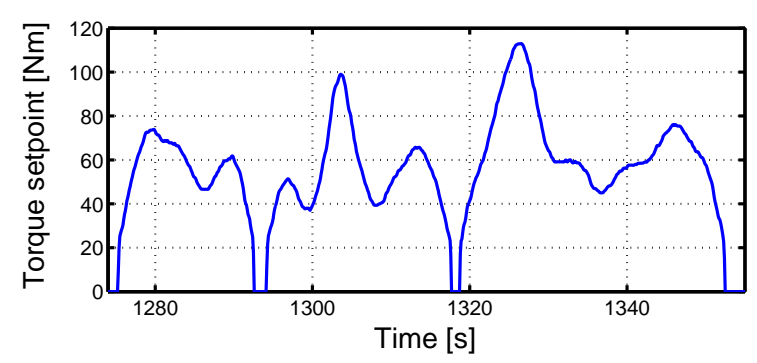

(b) Engine torque setpoint

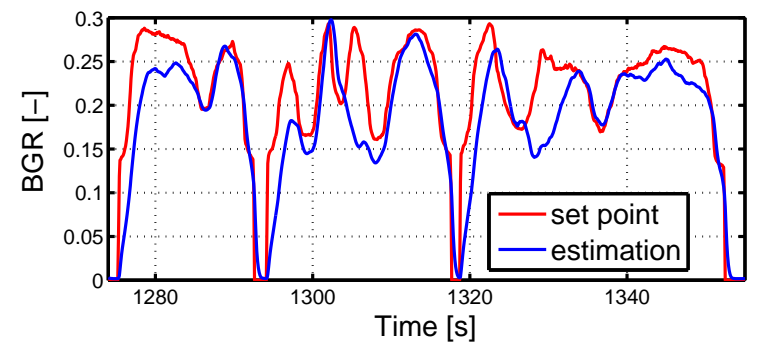

(c) BGR

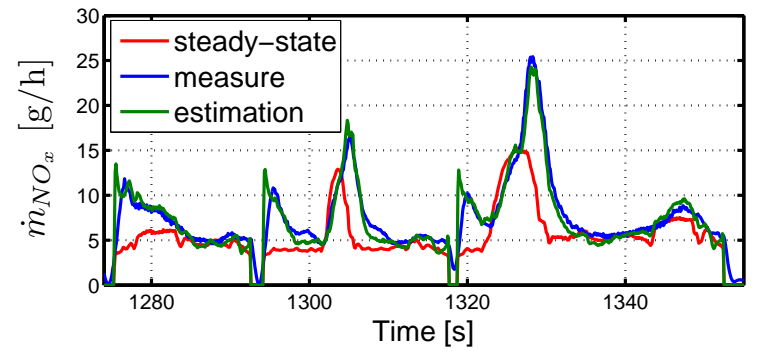

(d) $\mathrm{NO}_{\mathrm{x}}$ mass flow

Figure 24: Comparaison of estimated and measured $\mathrm{NO}_{\mathrm{x}}$ mass flow on a portion of a WLTC cycle. 


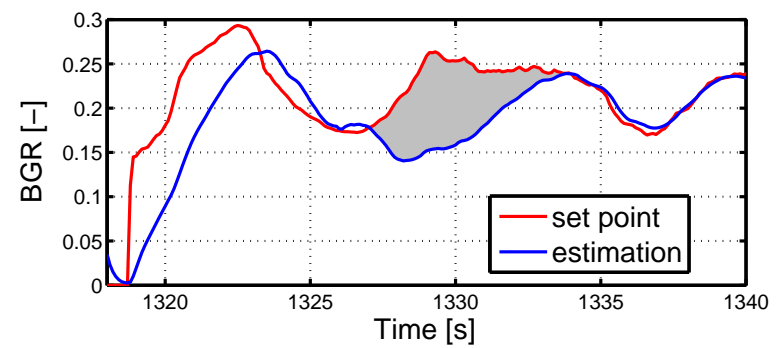

(a) BGR

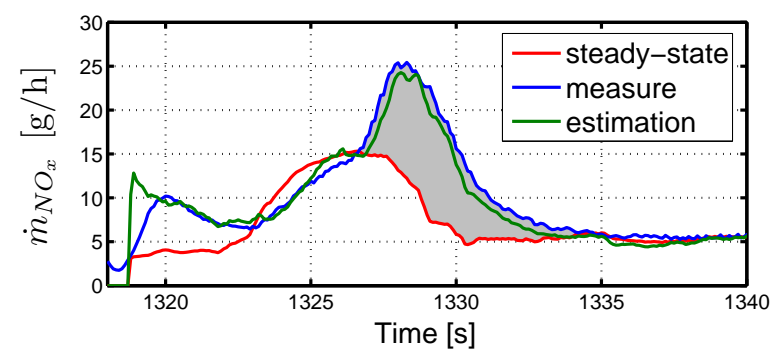

(b) $\mathrm{NO}_{\mathrm{x}}$ mass flow

Figure 25: Impact of $\mathrm{BGR}$ errors on $\mathrm{NO}_{\mathrm{x}}$ emissions during transient operations.

The estimated $\mathrm{NO}_{\mathrm{x}}$ emissions are compared with the experimental data in terms of total mass of $\mathrm{NO}_{\mathrm{x}}$ produced during a driving cycle (figure 26a) and of $\mathrm{NO}_{\mathrm{x}}$ transient part (figure 26b). Three different driving cycles are tested: NEDC, WLTC and FTP (Federal Test Procedure). These cycles are realized on three different vehicles to obtain different trajectories of engine speed and torque setpoint for a same trajectory of vehicle speed. The model is able to accurately estimate the total mass of $\mathrm{NO}_{\mathrm{x}}$ produced during a driving cycle, the RMSE being about $5 \%$ for the tested cycles. Moreover, it provides a correct order of magnitude of $\mathrm{NO}_{\mathrm{x}}$ transient part.

\section{Conclusion}

\section{Appendix A. Experimental setup}

Experimental data measured on four-cylinder, direct-injection diesel engines, equipped with a High Pressure (HP) Exhaust Gas Recirculation (EGR) loop, 


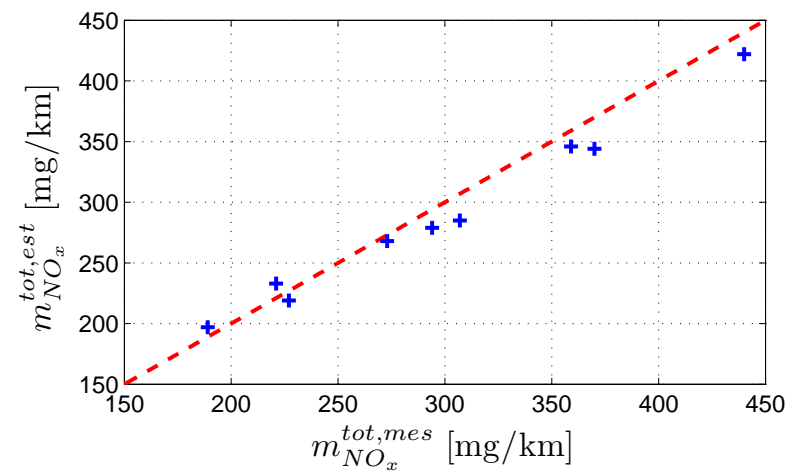

(a) Total mass of $\mathrm{NO}_{\mathrm{x}}$

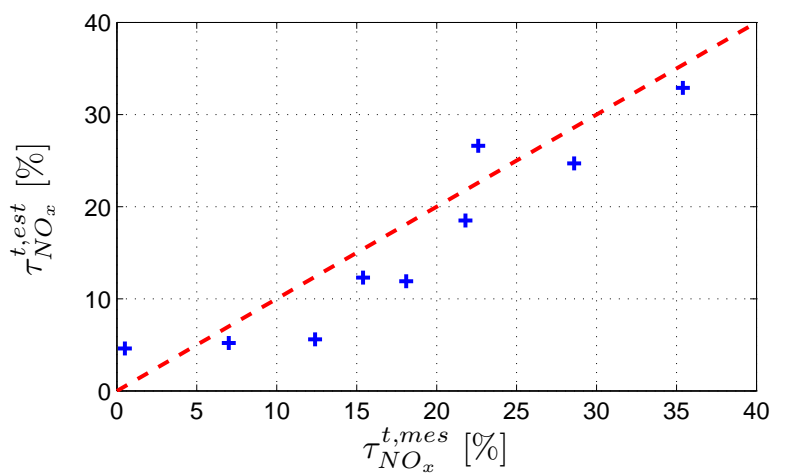

(b) $\mathrm{NO}_{\mathrm{x}}$ transient part

Figure 26: Comparison of estimated total mass of $\mathrm{NO}_{\mathrm{x}}$ and $\mathrm{NO}_{\mathrm{x}}$ transient part with experimental data for three driving cycles realized on three vehicles. The red dotted line represents the first bisector of the plan. 
are employed for the calibration and validation of the models. The main characteristics of the engines are summarized in table A.4.

Table A.4: Main characteristics of the engines.

\begin{tabular}{|c|c|c|c|}
\hline Characteristic & Unit & Engine A & Engine B \\
\hline Displacement & 1 & 2.0 & 1.5 \\
\hline Displacement per cylinder & $\mathrm{cm}^{3}$ & 499.0 & 365.2 \\
\hline Bore & $\mathrm{mm}$ & 84 & 76 \\
\hline Stroke & $\mathrm{mm}$ & 90 & 80.5 \\
\hline Compression ratio & - & 16 & 15.7 \\
\hline Engine speed range & $\mathrm{rpm}$ & $1000-3250$ & $1000-4000$ \\
\hline IMEP range & $\mathrm{bar}$ & $2-14$ & $2-20$ \\
\hline
\end{tabular}

The sensor setup includes standard air path sensors for the measurement of air mass flow, intake manifold pressure and temperature, as well as a fuel mass flow meter. During the experimental tests, the cylinder pressure is measured in each cylinder. As the cylinder-to-cylinder dispersion is low, the pressure is averaged on the four cylinders. A Horiba MEXA 7000 gas analyzer is used to measure $\mathrm{NO}_{\mathrm{x}}$ molar fractions in the exhaust gases.

For each engine, the steady-state experimental data set is obtained during two kinds of tests. The first data set is obtained in nominal operating conditions. These data are measured during the engine calibration phase and thus, they do not require any specific tests. During this phase, IMEP variations are realized for given engine speeds. The ranges of engine speed and IMEP variations are given in table A.4. The second data set is obtained by varying engine settings for given engine speed and torque. These tests are realized on about fifteen 
operating points allotted in the engine operating range. For each operating point, the BGR and the SOC are varied from their nominal values. An example of such variations is represented in figure A.27. BGR variations are realized by modifying the air mass flow setpoint for given SOC. These variations reproduce the effects of BGR errors during transient operations. A closed-loop control of the SOC based on the cylinder pressure is used and the Start Of Injection (SOI) is adapted to reach the desired value of the SOC. SOC variations are also realized by modifying the SOI for given BGR. In both cases, pilot and post-injections phasing are modified to keep constant delays between the injections.

The complete steady-state data set are used for the model validation. The calibration data sets are much smaller than the ones used for validation (table A.5. Indeed, for each engine operating points, only a variation of $F_{1}$ for $\theta_{\text {soc }}=\theta_{\text {soc }}^{\text {ss }}\left(\right.$ red squares in figure A.27) and a variation of $\theta_{\text {soc }}$ for $F_{1}=F_{1}^{s s}$ (blue diamonds in figure A.27) are kept for identification.

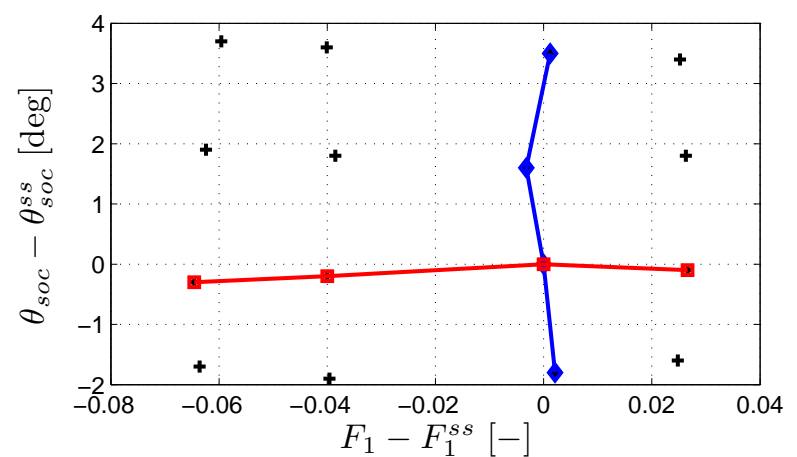

+ validation

$\multimap$ calibration: $\theta_{\text {soc }}$ variation

$\rightarrow$ calibration: $F_{1}$ variation

Figure A.27: Example of BGR and SOC variations for given engine speed and torque.

\section{Appendix B. Nomenclature}

Parameters \& Variables 
Table A.5: Number of operating points used for model calibration and validation.

\begin{tabular}{|c|c|c|}
\cline { 2 - 3 } \multicolumn{1}{c|}{} & Engine A & Engine B \\
\hline Identification & 216 & 324 \\
(including nominal points) & $(25)$ & $(229)$ \\
\hline Validation & 313 & 183 \\
\hline Total & 529 & 507 \\
\hline
\end{tabular}

\begin{tabular}{|c|c|}
\hline$E_{a} \ldots \ldots \ldots \ldots$ Activation energy & $\mathrm{J} \cdot \mathrm{mol}^{-1}$ \\
\hline$F_{1} \ldots \ldots \ldots \ldots$ Intake burned gas ratio & - \\
\hline$F_{2} \ldots \ldots \ldots$ Exhaust equivalence ratio & - \\
\hline ..... Molar enthalpy & $\mathrm{J} \cdot \mathrm{mol}^{-1}$ \\
\hline \multirow[t]{3}{*}{$k \ldots \ldots \ldots \ldots$ Kinetical constant } & $\mathrm{m}^{3}$ \\
\hline & $\mathrm{mol}^{-1}$ \\
\hline & $\mathrm{s}^{-1}$ \\
\hline$k_{n, \text { air }}$ Ratio between molar fractions of & - \\
\hline \multicolumn{2}{|l|}{$\mathrm{N}_{2}$ and $\mathrm{O}_{2}$ in fresh air } \\
\hline ...........Mass & $\mathrm{kg}$ \\
\hline .... Mass flow & $\mathrm{kg} \cdot \mathrm{s}^{-1}$ \\
\hline \multirow[t]{2}{*}{$M \ldots \ldots \ldots \ldots \ldots \ldots$ Molar mass } & $\mathrm{kg}$ \\
\hline & $\mathrm{mol}^{-1}$ \\
\hline ....... Molar quantity & mol \\
\hline ........ Engine speed & $\mathrm{rpm}$ \\
\hline ...... Pressure & $\mathrm{Pa}$ \\
\hline$\ldots \ldots \ldots \ldots$ Energy & $\mathrm{J}$ \\
\hline .... Lower heating value & $\mathrm{J} \cdot \mathrm{kg}^{-1}$ \\
\hline \multirow[t]{2}{*}{$r \ldots \ldots \ldots \ldots \ldots$ Gas constant } & $\mathrm{J} \cdot \mathrm{kg}^{-1}$. \\
\hline & $\mathrm{K}^{-1}$ \\
\hline
\end{tabular}




\begin{tabular}{|c|c|}
\hline$R \ldots \ldots \ldots$ Universal gas constant & $\begin{array}{l}\mathrm{J} \cdot \mathrm{mol}^{-1} \cdot \\
\mathrm{K}^{-1}\end{array}$ \\
\hline$T \ldots \ldots \ldots \ldots \ldots$ Temperature & $\mathrm{K}$ \\
\hline$t \ldots \ldots \ldots \ldots \ldots \ldots \ldots \ldots \ldots$ Time & $\mathrm{s}$ \\
\hline$\ldots \ldots$ Volume & $\mathrm{m}^{3}$ \\
\hline$x \ldots \ldots \ldots \ldots \ldots$ Mass fraction & - \\
\hline ......... Molar fraction & - \\
\hline$[i]$. Molar concentration of a species $i$ & $\mathrm{~mol} \cdot \mathrm{m}^{-3}$ \\
\hline$\gamma \ldots \ldots \ldots \ldots$ Ratio of specific heats & - \\
\hline$\eta_{v} \ldots \ldots \ldots \ldots$ Volumetric efficiency & - \\
\hline$\theta \quad \ldots \ldots \ldots \ldots \ldots \ldots$ Crank angle & $\operatorname{deg}$ \\
\hline$\omega \ldots \ldots \ldots$. . . . . Rotational speed & $\mathrm{rad} \cdot \mathrm{s}^{-1}$ \\
\hline
\end{tabular}

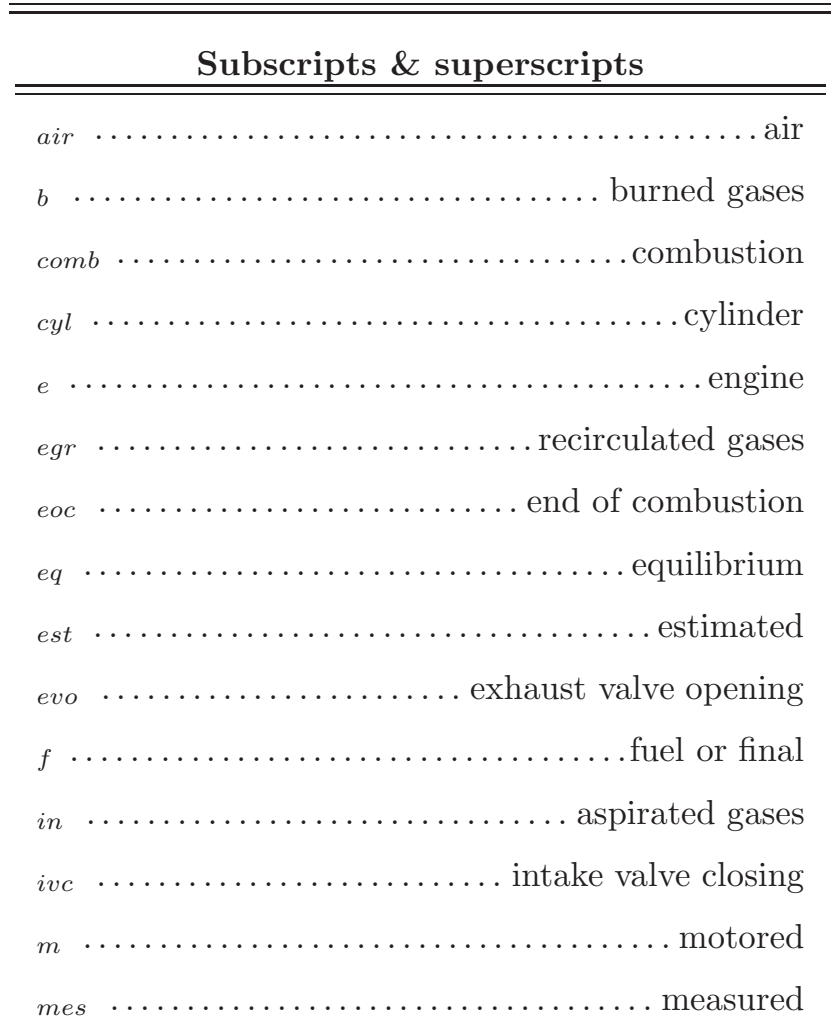




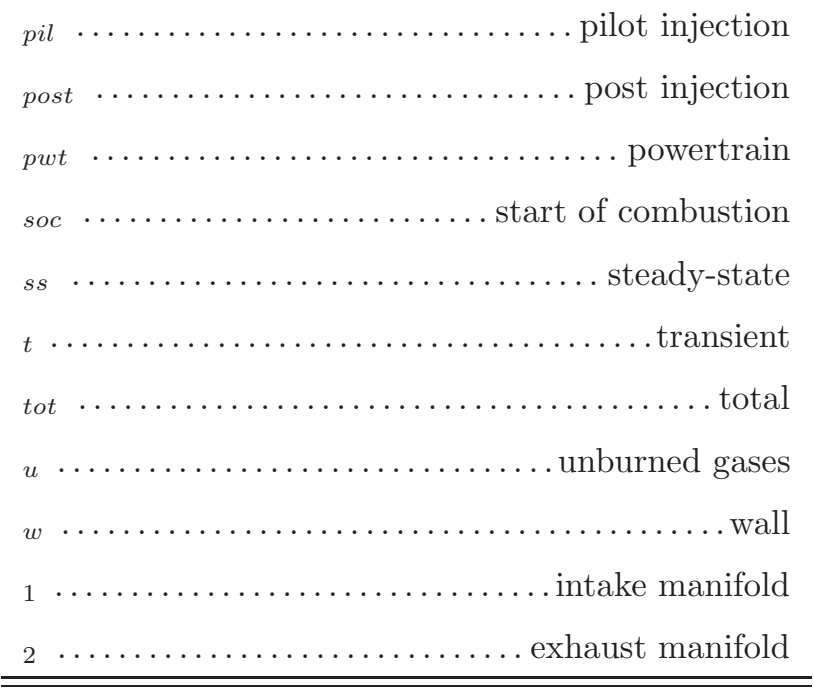

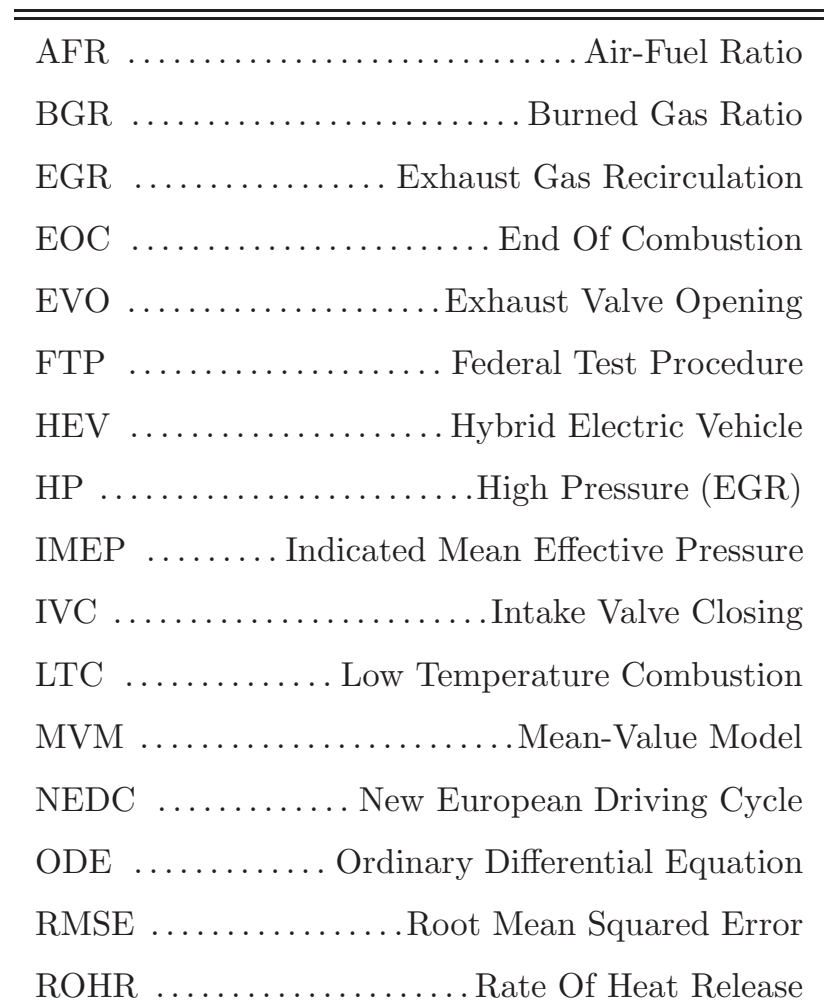




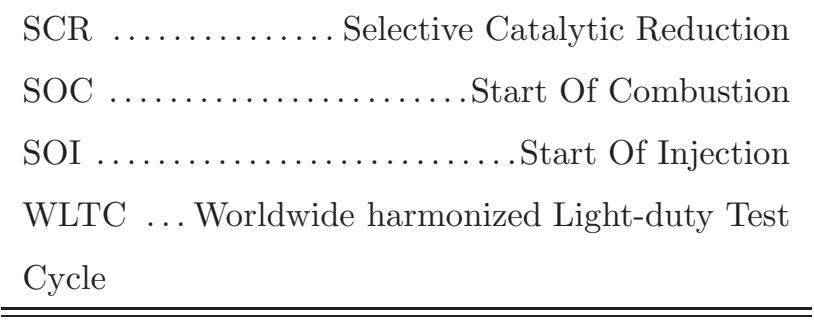

\section{References}

[1] J. Asprion, O. Chinellato, L. Guzzella, A fast and accurate physics-based model for the NOx emissions of diesel engines, Applied Energy.

[2] M. Benz, M. Hehn, C. Onder, L. Guzzella, Model-based actuator trajectories optimization for a Diesel engine using a direct method, Journal of Engineering for Gas Turbines and Power 133 (3).

[3] L. Guzzella, C. Onder, Introduction to modeling and control of internal combustion engine systems, 2nd Edition, Springer Verlag, 2004.

[4] C. Quérel, O. Grondin, C. Letellier, State of the art and analysis of control oriented NOx models, SAE International 2012-01-0723.

[5] W. Park, J. Lee, K. Min, J. Yu, S. Park, S. Cho, Prediction of real-time NO based on the in-cylinder pressure in diesel engines, Proceedings of the Combustion Institute.

[6] J.-C. Schmitt, M. Fremovici, O. Grondin, F. Le Berr, Compression ignition engine model supporting powertrain development, in: Proceedings of the ECOSM'09 - IFAC Workshop on Engine and Powertrain Control, Simulation and Modeling, Rueil-Malmaison, France, 2009, pp. 75-82.

[7] C. Quérel, A. Bonfils, O. Grondin, Y. Creff, Control of a SCR system using a virtual NOx sensor, in: Proceedings of the 7th IFAC Symposium Advances in Automotive Control, Tokyo, Japan, 2013.

[8] M. Hillion, Transient combustion control of internal combustion engines, Ph.D. thesis, MINES Paris Tech (2009). 
[9] O. Grondin, L. Thibault, C. Quérel, Transient torque control of a diesel hybrid powertrain for NOx limitation, in: Proceedings of the E-COSM'12 IFAC Workshop on Engine and Powertrain Control, Simulation and Modeling, Rueil-Malmaison, France, 2012.

[10] C. Barba, C. Burkhardt, K. Boulouchos, M. Bargende, A phenomenological combustion model for heat release rate prediction in high-speed DI Diesel engines with common-rail injection, SAE Technical Paper 2000-01-2933.

[11] N. Watson, A. Pilley, M. Marzouk, A combustion correlation for diesel engine simulation, SAE Technical Paper 800029.

[12] C. Ferguson, Internal combustion engines, John Wiley, New York, 1986.

[13] J. Heywood, Internal combustion engine fundamentals, McGraw-Hill New York, 1988.

[14] P. Vervisch, O. Colin, J. Michel, N. Darabiha, NO relaxation approach (NORA) to predict thermal NO in combustion chambers, Combustion and Flame 158.

[15] R. Egnell, Combustion diagnostics by means of multizone heat release analysis and NO calculation, SAE Technical Paper 981424.

[16] Y. Zeldovich, The oxidation of nitrogen in combustion and explosion, Acta Physicochemica 21 (4) (1946) 577-628.

[17] G. Lavoie, J. Heywood, J. Keck, Experimental and theoretical study of nitric oxide formation in internal combustion engines, Combustion Science and Technology 1 (4) (1970) 313-326.

[18] C. Quérel, Modélisation des émissions de NOx pour le contrôle des moteurs diesel, Ph.D. thesis, Université de Rouen (2013).

[19] C. Quérel, O. Grondin, C. Letellier, A semi-physical NOx model for diesel engine control, SAE Technical Paper 2013-01-0356. 
[20] G. Woschni, A universally applicable equation for the instantaneous heat transfer coefficient in the internal combustion engine, SAE Technical Paper 670931.

[21] R. Finesso, E. Spessa, Real-time predictive modeling of combustion and NOx formation in diesel engines under transient conditions, SAE Technical Paper 2012-01-0899.

[22] C. Rakopoulos, D. Hountalas, E. Tzanos, G. Taklis, A fast algorithm for calculating the composition of diesel combustion products using 11 species chemical equilibrium scheme, Advances in Engineering Software 19 (2) (1994) 109-119.

[23] C. Bowman, Kinetics of pollutant formation and destruction in combustion, Progress in energy and combustion science 1 (1) (1975) 33-45.

[24] J. Benesty, J. Chen, Y. Huang, I. Cohen, Pearson correlation coefficient, Noise Reduction in Speech Processing 2 (2009) 1-4.

[25] G. Heider, Rechenmodell zur vorausberechnung der NO-emission von dieselmotoren, Ph.D. thesis, TU München (1996).

[26] E. Alfieri, Emissions-controlled diesel engine, Ph.D. thesis, ETH Zürich (2009).

[27] J. Arrègle, J. López, C. Guardiola, C. Monin, Sensitivity study of a NOx estimation model for on-board applications, SAE Technical Paper 2008-010640.

[28] C. Vigild, C.-F. Tumelaire, D. Röttger, E. Karvounis, P. Calendini, Towards generic model based engine control - the concept, in: Proceedings of the E-COSM'06 - IFAC Workshop on Engine and Powertrain Control, Simulation and Modeling, Rueil-Malmaison, France, 2006, pp. 95-102.

[29] D. Lahiri, P. Mehta, R. Poola, R. Sekar, Utilization of oxygen-enriched air in diesel engines: Fundamental considerations, Tech. rep., Argonne National Lab., IL (United States) (1997). 
[30] T. Shiozaki, H. Nakajima, Y. Kudo, A. Miyashita, Y. Aoyagi, The analysis of combustion flame under EGR conditions in a DI diesel engine, SAE Technical Paper 960323. 